The University of Maine

DigitalCommons@UMaine

Electronic Theses and Dissertations

Fogler Library

$5-2003$

\title{
Tidal Modulation of Nocturnal Vertical Migration from the Benthos: A High-resolution Acoustic Analysis
}

Leslie E. Taylor

Follow this and additional works at: http://digitalcommons.library.umaine.edu/etd

Part of the Oceanography Commons

\section{Recommended Citation}

Taylor, Leslie E., "Tidal Modulation of Nocturnal Vertical Migration from the Benthos: A High-resolution Acoustic Analysis" (2003). Electronic Theses and Dissertations. 171.

http://digitalcommons.library.umaine.edu/etd/171

This Open-Access Thesis is brought to you for free and open access by DigitalCommons@UMaine. It has been accepted for inclusion in Electronic Theses and Dissertations by an authorized administrator of DigitalCommons@UMaine. 


\title{
TIDAL MODULATION OF NOCTURNAL VERTICAL MIGRATION FROM THE BENTHOS: A HIGH-RESOLUTION ACOUSTIC ANALYSIS
}

By

\author{
Leslie E. Taylor
}

B.S. Prescott College, 1998

\author{
A THESIS \\ Submitted in Partial Fulfillment of the \\ Requirements for the Degree of \\ Master of Science \\ (in Oceanography) \\ The Graduate School \\ The University of Maine \\ May, 2003
}

Advisory Committee:

Peter Jumars, Professor of Marine Sciences and Oceanography, Advisor

Neal Pettigrew, Associate Professor of Oceanography

Les Watling, Professor of Oceanography 


\section{LIBRARY RIGHTS STATEMENT}

In presenting this thesis in partial fulfillment of the requirements for an advanced degree at The University of Maine, I agree that the Library shall make it freely available for inspection. I further agree that permission for "fair use" copying of this thesis for scholarly purposes may be granted by the Librarian. It is understood that any copying or publication of this thesis for financial gain shall not be allowed without my written permission.

Signature: Lesti \& Tayth

Date: $5 / 6 / 03$ 


\title{
TIDAL MODULATION OF NOCTURNAL VERTICAL MIGRATION FROM \\ THE BENTHOS: A HIGH-RESOLUTION ACOUSTIC ANALYSIS
}

\author{
By Leslie E. Taylor \\ Thesis Advisor : Dr. Peter Jumars \\ An Abstract of the Thesis Presented \\ in Partial Fulfillment of the Requirements for the \\ Degree of Master of Science \\ (in Oceanography) \\ May, 2003
}

Emergence-trap sampling has shown that several species living primarily on or in the sediment emerge nightly into the water column. This behavior was investigated using acoustic and traditional sampling methods. A TRACOR acoustic profiler, TAPS, was mounted on the sea bottom, looking upwards in approximately $10 \mathrm{~m}$ of water in the Damariscotta River estuary, Walpole, Maine. TAPS emits high-frequency (265-3000 $\mathrm{kHz}$ ) sonar pulses and each minute measures backscatter from $12.5-\mathrm{cm}$ range bins in the water column. TAPS data showed a distinct increase in backscatter in the water column most evenings, beginning around or after dusk and terminating before dawn. The duration, intensity and initiation time of this emergence pattern varied. Emergence-trap samples suggest that the acoustic signal was dominated by Neomysis Americana and Crangon septemspinosa. In addition, there appeared to be more than one emergence event per night. A higher-density emergence event occurred shortly after the highest tidal speeds, as the tidal currents were decelerating. High-density emergence events were observed at a fixed stage (approximately 3.5 - 4 hours after local slack tide) of both incoming and outgoing tides. Although "emergence" of hyperbenthic organisms has only 
been documented as occurring at night, a similar increase in backscatter was observed during the day at the same stage of the tide as nocturnal emergence events. The backscatter increase measured during the day, however, was significantly less than at night. Our acoustic results suggest that emergence is tidally modulated. They also suggest that emergence in an environment with strong tidal velocities may be more temporally complex than previous studies by non-acoustic means have been able to resolve. 


\section{ACKNOWLEDGEMENTS}

I wish to express sincere gratitude for the guidance and opportunities provided by my advisor Peter Jumars and by my committee members, Les Watling and Neal Pettigrew. I would like to especially thank and recognize Shawn Shellito for his tireless efforts to keep TAPS up and running. Additionally I would like to thank my lab-mates Heather Abello and Kelly Dorgan. 
TABLE OF CONTENTS

ACKNOWLEDGEMENTS ................................................ ii

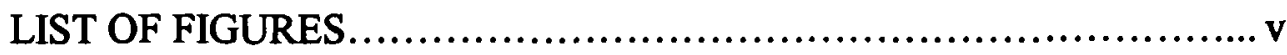

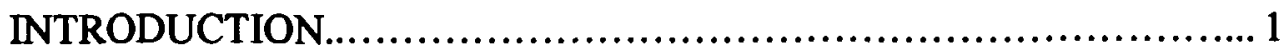

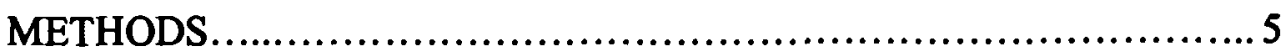

Acoustic data collection..................................5

Emergence-trap sample collection and processing..........6 6

Other environmental measurements.......................8

Analyses...............................................

Inversion model..................................9

TAPS data quality control......................... 9

Emergence algorithm............................11

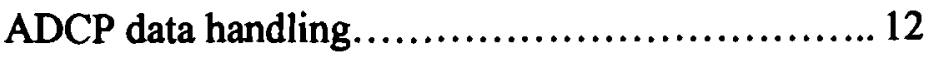

Transmissometer data............................ 12

Statistical analyses................................ 12

Tidal modulation...........................12

Trap samples................................14

RESULTS AND DISCUSSION ............................... 14

General emergence patterns........................ 14

Comparison of "delay periods" ...............16

Comparison of emergence magnitudes........20

Interaction effects..........................24 
Tidal modulation..................................25

Time series results.................................34

Transmissometer results..........................40

Trap samples.................................... 45

Responsibility for the high-density emergence event : possible scenarios................ 52

CONCLUSION..................................................... 54

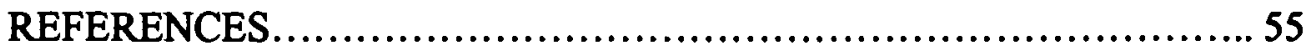

APPENDIX: Original Matlab Programs ...................................58

BIOGRAPHY OF THE AUTHOR $\ldots \ldots \ldots \ldots \ldots \ldots \ldots \ldots \ldots \ldots \ldots \ldots \ldots \ldots \ldots \ldots \ldots$ 


\section{LIST OF FIGURES}

Figure 1. Total Nocturnal Biovolume (19August 2002).................... 15

Figure 2. Total Daytime Biovolume (10 August 2002)................... 17

Figure 3. Delay Period for Daytime and Nighttime Emergence Events......... 18

Figure 4. Delay Period for Daytime and Nighttime Emergence Events

Grouped by Type of Tide........................................ 19

Figure 5. Delay Period for Emergence Events on Incoming and

Outgoing Tides................................................. 21

Figure 6. Delay Period for Emergence Events on Incoming and Outgoing

Tides Grouped by Time of Day (Day/Night) ................... 22

Figure 7. Magnitude of Daytime and Nighttime Emergence Events............23

Figure 8. Tidal Modulation of a Nocturnal Emergence Event

(July-September 2002) ..................................... 26

Figure 9. Tidal Modulation of a Nocturnal Emergence Event

(August and September 2001) .............................. 27

Figure 10. Tidal Modulation of a Diurnal Emergence Event (August 2002)... 28

Figure 11. Tidal Modulation of Diurnal and Nocturnal Emergence Events. ...29

Figure 12 Local Tidal Speed $0.1 \mathrm{~m}$ above the Bottom Subsequent to High

Tide In Boothbay Harbor (3 August 2002) ….................... 30

Figure 13. Current Speed at Initiation Time of an Emergence Event.............31

Figure 14. Histogram of Current Speed $0.1 \mathrm{~m}$ above the Bottom at the Initiation

Times of Emergence Events.................................... 32

Figure 15. Histogram of Current Speed $0.1 \mathrm{~m}$ above the Bottom at the Initiation 
Times of Emergence Events Grouped Type of Tide and

Time of Day.

33

Figure 16. Histogram of Tidal Speed $0.1 \mathrm{~m}$ Above the Bottom : 1-17 August

2002 35

Figure 17. The Influence of Current Speed on the Magnitude of

Emergence Events...........................................36

Figure 18. Autocorrelogram of Total Biovolume on the Scale of Hours

(1-28 August $2002: 2-5 \mathrm{~m}$ above TAPS).

Figure 19. Autocorrelogram of Total Biovolume on the Scale of Days

(1-28 August $2002: 2-5 \mathrm{~m}$ above TAPS) 38

Figure 20. Autocorrelogram of Tidal Current Speed near the Benthos

on the scale of Hours.

Figure 21. Cross-correlogram of Total Biovolume and Bottom Tidal Speed on the scale of Hours.

Figure 22. Cross-correlogram of Total Biovolume and Bottom Tidal Speed on the scale of Days

Figure 23. Backscatter (Sv) from $265 \mathrm{kHz}$ Channel (20-23 July 2001).........43

Figure 24. Attenuation Coefficient (c) : 18-25 November 2002.............. 44

Figure 25. Autocorrelogram of Attenuation Coefficient (c) in Damariscotta

River on the Scale of Hours. .46

Figure 26. Autocorrelogram of Attenuation Coefficient (c) in Damariscotta

River on the Scale of Days

Figure 27. Total Biovolume (19-21 August 2002) 48 
Figure 28. Number of Neomysis americana Captured in the First versus the Second Part of the Night.....................................5 50 


\section{INTRODUCTION}

Several species of macrofauna living in, on or near the sediment (infaunal, epi- or hyperbenthic organisms) in some coastal and estuarine systems emerge nightly into the water column (e.g. Wang and Dauvin 1994; Oishi and Saigusa 1997). This regular migration resembles the better-studied vertical migration of some open-ocean zooplankton. In the open ocean, migrating zooplankton have been visualized by examining acoustic backscatter. Backscatter is the sound reflecting from an object back toward its source. The large groups of migrating zooplankton that cause extensive backscatter in the open ocean are collectively called the deep scattering layer. This study used acoustic methods to resolve analogous migration patterns of hyperbenthic animals in shallow water.

Acoustic methods have proven effective in measuring such vertical migrations in a lake (Trevorro and Tanaka 1997) and in a shallow marine setting at West Sound, Orcas Island, Washington (Kringel et al. 2003). Because an acoustic instrument does not disturb the benthos, acoustic methods are particularly effective at monitoring near-bottom plankton, which are notoriously difficult to sample using conventional methods. Most importantly, acoustic methods of observation provide excellent spatial and temporal resolution.

For this project, a TRACOR acoustic profiler (TAPS-6 from BAE SYSTEMS, San Diego, CA), abbreviated as TAPS, was deployed in the Damariscotta River estuary during the summers of 2001 and 2002. TAPS as we deploy it is a multi-frequency (265 $\mathrm{kHz}, 420 \mathrm{kHz}, 720 \mathrm{kHz}, 1100 \mathrm{kHz}, 1865 \mathrm{kHz}, 3 \mathrm{MHz}$ ), moored, inverted echosounder, measuring backscatter in a series of $12.5-\mathrm{cm}$ range bins directly above the transducers 
every minute. TAPS data showed a distinct increase in backscatter in the water column most evenings, beginning after dusk and terminating before dawn.

High-resolution observations are required to study the timing and intensity of vertical migration from the benthos (benthic emergence) and to suggest what drives the migratory behavior of a species in a given environment. Nocturnal migration by the deep scattering layer in the open ocean is believed to be cued by light levels or rates of change in them. Prey species feed in shallower waters under cover of darkness, then descend to deeper and darker water during daylight to avoid visual predators (Lalli and Parsons 1997). Light can act as a similar driver in shallow water (Alldredge and King 1980; Ohlhorst 1982; Kaartvedt 1986). Hyperbenthic animals may emerge into the water column after dark to feed or molt, descending at dawn to avoid predation. In a shallow environment, prey species cannot descend beyond the level of light penetration and may instead utilize the turbid water and detrital material on the benthic surface for concealment during the day.

Another suggested driver of vertical migration from the benthos is the avoidance of hypoxia (La Row 1970). Benthic diatoms could produce a diurnal cycle of oxygen availability, photosynthesizing and providing oxygen to the sediment during the day and using up oxygen at night. Organisms might enter the water column at night to retreat from the periodically anoxic conditions of the sediment.

Lastly, tidal currents could drive vertical migration. This paper examines the hypothesis that benthic emergence is tidally modulated. Vertical migration in an environment with strong tidal currents leads to horizontal transport. This consequence suggests that tidally modulated emergence is a mechanism enabling an organism to 
control its position within the estuary (Hill 1991a,b; Wooldridge and Erasmus 1980). Vertically migrating organisms can take advantage of changes in current direction to achieve net horizontal transport. A diurnal vertical migration modulated by the tidal regime is utilized as a means of dispersal by shrimp larvae (Rothlisberg et al. 1983) and as a means of estuarine retention by larval fishes (Fortier and Leggett 1983) and crab larvae (DeVries et al. 1994).

Tidal modulation of benthic emergence could be cued by changes in the magnitude of tidal currents and not just changes in the direction of tidal currents. Emerging organisms may coordinate their vertical migration with times of high velocity and turbulence intensity. Turbulence in the water column can result in resuspension of sediment from the seafloor, possibly camouflaging prey species from both visual and tactile predators.

Although acoustic instruments provide excellent spatial and temporal resolution, backscatter measurements can illuminate only spatio-temporal patterns of abundance of objects that cause backscatter. They cannot tell what objects create the patterns. For this project, "ground truthing" was performed with daily emergence-trap samples. These samples give both an inventory of vertically migrating species and a sense of the magnitude of nocturnal emergence events. The primary species found in the emergence traps were Neomysis americana and Crangon septemspinosa. Amphipod and cumacean species were also captured.

It is plausible that the animals captured in emergence traps are those responsible for acoustically observed nocturnal increases in backscatter. Many different mysid species have been shown to migrate vertically (Mauchline 1980). While there is nothing 
in the literature to suggest that Crangon vertically migrate, Crangon are nocturnal, opportunistic predators that consume mysids as their predominant food source (Oh et al. 2001; Wilcox and Jeffries 1974). They may migrate from the benthos in some environments in pursuit of their prey.

Also, after multi-frequency inversion to obtain volume estimates from backscatter measurements (Holliday 1977; Greenlaw and Johnson 1983; Holliday 1993; McGehee et al. 1998), the size distribution of organisms caught in the emergence traps was reasonably consistent with the distribution of size spectra estimated. Biovolume estimates show two distinct size classes, which mirror the non-overlapping size classes of Crangon and mysids. Estimated sizes were reasonably close to measured sizes of organisms captured in our emergence traps as also found by Kringel et al. (2003) using inversion models more closely tailored to mysid morphology.

Both mysids and Crangon are preferred prey of sea robins, flounders and many other fish species (Manderson et al. 1999; Moore and Moore 1976, Hostens and Mees 1999) and form the base of an estuarine food web. Organisms nocturnally emerging from the benthos provide a trophic link between benthic and pelagic systems. Emergence behavior may influence the physical and chemical properties of the benthos through a type of bioturbation as organisms daily unbury and rebury themselves.

This project addresses several questions. First, can a pattern resembling vertical migration be resolved using acoustics in an environment with strong currents? Can the high resolution observations provided by acoustic technology enable us to quantify the timing and magnitude of benthic emergence? Second, can we detect the influence of the 
tides on the acoustically observed pattern? Lastly, who or what is responsible for the acoustically observed pattern?

\section{METHODS}

\section{Acoustic data collection}

During the summers of 2001 and 2002, TAPS was mounted on the sea bottom, looking upward in approximately $10 \mathrm{~m}$ of water in the Damariscotta River estuary, Walpole, Maine. The Damariscotta River estuary is a tidal, well mixed, and receives very little freshwater input. Its tides are semi-diurnal with velocities on the order of 25 $\mathrm{cm} \mathrm{s}^{-1}$. Substrate in the study area was sandy silt.

TAPS was deployed in a steel frame and positioned so that all 6 transducers (265 $\mathrm{kHz}, 420 \mathrm{kHz}, 720 \mathrm{kHz}, 1.1 \mathrm{MHz}, 1.85 \mathrm{MHz}$ and $3.0 \mathrm{MHz}$ ) faced upward. We used three different TAPS instruments during this study. In 2001, we used an instrument, TAPS-X, on long-term loan from BAE SYSTEMS. In 2002, we used two different TAPS instruments, designated TAPS-J and TAPS-M. Because they are not identical in hardware performance (although each unit is calibrated annually), we recorded which unit was being used. Because of the frame, the transducers were approximately $1 \mathrm{~m}$ above the substrate. As a result, all depth-bin measurements are discussed here as meters above TAPS rather than as meters above the substrate.

TAPS was placed by divers $50-100 \mathrm{~m}$ from the pier at the Darling Marine Center. Power was supplied to TAPS from the pier through a 500-m, multi-conductor cable. Once every minute, each transducer of TAPS emitted 24 sets of high-frequency sonar pulses and measured backscatter from $12.5-\mathrm{cm}$ range bins in the water column directly 
above TAPS. Within TAPS, the backscatter measurements of each set were averaged.

All 24 averages were then summed to produce an output representing the backscatter for one minute. This value was transmitted to a laptop computer on the pier through the conductor cable.

An acoustic Doppler current profiler (Workhorse Series Monitor $600 \mathrm{kHz}$ ADCP, RD Instruments, San Diego, CA) was also deployed in the same area as TAPS. Like TAPS, the ADCP was connected through a multi-purpose cable to a power supply and laptop computer on the pier. The ADCP was deployed on a steel frame that places the transducers approximately $0.25 \mathrm{~m}$ above the sediment. The first bin started at $1.22 \mathrm{~m}$. There were 45 pings/ensemble. The ensemble length was $59.81 \mathrm{~s}$. The ADCP measured the direction and magnitude of tidal currents in 10-cm vertical depth bins in the water column directly above it. Adjustments were made when comparing TAPS and ADCP data so as to compare bins at the same height above the sediment.

\section{Emergence-trap sample collection and processing}

During the summer and fall of 2001 and 2002, four emergence traps were deployed in the area around TAPS an average of four times per week. Traps were deployed for approximately $24-\mathrm{h}$ periods beginning around 1300 hours EDT. The basic trap design is pyramidal with a $1-\mathrm{m}^{2}$ base made of aluminum angle stock that penetrates into the sediment. The faces of the pyramid are covered with $1-\mathrm{mm}^{\mathrm{Nitex}}{ }^{\mathrm{TM}}$ mesh. At the top of the trap is a $2-\mathrm{cm}$ diameter tube leading into a collection bottle. The collection bottle has a mesh-covered hole at the top to allow ambient water to circulate into the bottle and prevent hypoxia. Any emerging animals from the one-meter square beneath the trap will be funneled into the collection bottle if they continue to migrate vertically 
through the orifice. Although the traps are imperfect, e.g. they change the water flow regime above the sediment and may modify an animal's behavior, they do help us survey the potentially emerging taxa present in the environment.

In 2001 and the first part of 2002, two of the four traps deployed were of this basic design, whereas two were modifications of the basic trap. These modified traps were identical to the basic trap, but were elevated on steel legs above the sediment. For the remainder of 2002, all four traps deployed were of the basic design.

Two ropes were tied to each trap. A buoy was at one end of each rope. One rope was tied to the top of the trap, whereas the other was tied to a bottom corner of the trap. Traps were lowered using the rope tied to one of the four bottom corners. The trap descended on its side so as not to capture organisms from the water column. Once the trap was near the substrate, the rope attached to the top of the trap was pulled up a meter or so in order to right the trap, and then this line was used to lower the trap the remaining distance to the seabed.

Acoustic observations suggested that there were several emergence events throughout the night. To resolve whether these events represented multiple peaks of emergence by a single species or heterogeneity in emergence times among taxa or life stages, all four traps were also deployed for shorter periods during three consecutive days, 19-22 August 2002. Samples were collected and the traps redeployed at around 0800,1600 and again at around 0000 hours EDT daily.

Collected specimens were fixed in $10 \%$ formalin, then transferred to $70 \%$ ethanol. All samples were archived, so that we could use measurements made on them to correlate with acoustic measurements and to detect seasonal changes in emergence 
behavior. In some samples, the number of individuals of each species was counted. For the dominant species, Neomysis americana, individuals were sorted by sex and developmental stage.

\section{Other environmental measurements}

For some analyses, correlation with the time of low tide in Boothbay Harbor, ME, was examined as a proxy for tidal phase. The tide chart used was from the web site http://www2.shore.net/ mcmorran/tide/tideform.html. Times of civil twilight, sunrise and sunset were taken from the website http://aa.usno.navy.mil/data/docs/RS_One day.

In order to determine how much water clarity changes in the study site as a result of tidal currents, a transmissometer, an instrument that measures attenuation of a light beam, was placed near TAPS during 18-25 November, 2002. The question driving this deployment was whether some of the apparent emergence signal at the highest frequencies was instead resuspension of sediments. A Wet Labs (Corvallis, OR) C-Star transmissometer with a $10-\mathrm{cm}$ path length and a $660 \mathrm{~nm}$ wavelength was used. The transmissometer was oriented so that the beam was perpendicular to the direction of flow so as to minimize water turbulence in the beam's path. The transmissometer was fastened to a steel frame at the same height as the TAPS transducers. Voltage output was recorded by a Wet Labs Data Handler-4 (DH-4).

\section{Analyses}

All data processing of TAPS output was performed using MATLAB (Math Works, Inc. 24 Prime Park Way, Natick, MA 01760-1500) version 5.3. 


\section{Inversion model}

An acoustic inversion model uses backscatter measurement from six channels to estimate the volumetric abundance of particles of different sizes (Medwin and Clay 1998). The model that we used was an equivalent spherical radius model that came with the instrument. The model was developed by Charles Greenlaw of BAE systems. From a multi-frequency set of backscatter measurements the model estimates how much of the backscatter signal is likely to have come from particles of a given size, assuming that the particles are spheres. For small crustaceans, a factor of 4-5 can be used to estimate animal length from the calculated spherical radius (Pieper and Holliday 1984). Besides yielding size-class information, the inversion model also calculates the total volume of particles likely to have produced a multi-frequency measurement of backscatter. This total volume estimate will be called "biovolume" for the remainder of this paper, although it should be noted that the particles creating the backscatter used for the estimate are not necessarily living or even biogenic.

\section{TAPS data quality control}

As TAPS is a relatively new instrument, still in its beta testing phase, some shortcomings in the data and software processing needed to be addressed to facilitate analysis. The beam-spreading function used to get a measure of backscatter from distant height bins was imperfect, resulting in systematic bias in the backscatter measurements. Bins farther away from TAPS consistently gave higher estimates of backscatter than those close to TAPS. The consistency of the bias defied biological explanation and made it difficult to examine time variations in the data. As a result, I wrote an algorithm to minimize the gradient, i.e. a "gradient filter" (Appendix A). All data in 2002 were 
treated with the gradient filter before the inversion model was applied. However, as the gradient produced by the TAPS-X was substantially less steep than the gradient produced by the TAPS-J and TAPS-M (the instruments that we used in 2002), 2001 data used here have not been treated with the gradient filter. To see whether this inconsistency might produce artifactual differences in results between years the inversion model was applied to gradient-filtered and non-gradient-filtered measurements on several dates in 2001. Biovolume magnitudes calculated were only slightly different, and the spatial patterns of abundance and their temporal changes were identical.

Biovolume data were smoothed across time with an eleven-point running-median filter. This level of smoothing increased the signal-to-noise ratio in the data by eliminating some small-scale variability, yet it retained the larger features of interest. In order to retain high spatial resolution, data were not smoothed across depth bins. The data from the first two meters above TAPS were never used in analysis due to extreme variability in this region. The high variability was probably a result of ringing of the transducers in resonance with the steel frame.

During the summer of 2002 the time-stamp assigned by TAPS, as translated into MATLAB, functioned erratically. The time-stamp function assigns the data to successive, one-minute intervals, but clock drift or a software problem assigned some observations to the same minute and left some minutes without observations assigned. Most measurements nevertheless were taken approximately $60 \mathrm{~s}$ apart. Some measurements were legitimately missing, however (leaving a gap of more than $60 \mathrm{~s}$ between observations). I wrote a program to deal with these problems (Appendix A). 


\section{Emergence algorithm}

One of the most difficult tasks in this study of benthic emergence was objective definition of an emergence event. Since there appeared to be multiple emergence events each night (or one spatially and temporally complex single event), several algorithms were written for the data. Just as different human observers might select different emergence events as dominant, each algorithm defined a different event as "the" emergence. Unlike human observers, however, any one algorithm always finds the same result from the same data.

The algorithm selected for this work uses both the magnitude of increased abundance and the duration of the increase to define an event (Appendix A). For a given time period, this algorithm searches a strip from 2-5 m above TAPS to find the initiation time of the longest-lasting, highest-density event. This algorithm was used in examination of nighttime (1900-0700 hours) and daytime (0700-1900 hours) periods. Whereas benthic emergence (as defined in the introduction) occurs primarily at night, there are also times of higher density during the day. For simplicity, in this paper both nocturnal and diurnal times of increased density detected by the algorithm will be called "emergence events."

The emergence algorithm identifies observations above a threshold value in biovolume $\left(\mathrm{mm}^{3} \mathrm{~m}^{-3}\right)$. This threshold can vary from depth to depth or night to night. The algorithm searches each depth for observations above an arbitrarily low threshold. If there are more than 240 observations (minutes) above the selected value, the threshold is raised. Then the depth is searched again. The process repeats until fewer than or exactly 
240 observations fall above the threshold. The median threshold value used to find emergence for a given time period (over all depths searched) is used as for a measure of the "magnitude" of the event.

ADCP data handling

ADCP data were opened with RD Instruments' WINADCP program. Current magnitude and direction data were then exported as a MATLAB file for further use. For this environment, velocities measured by the ADCP were assumed to be tidal currents.

Transmissometer data

Transmissometer voltage output was downloaded from the DH-4 using Wet Labs' host program software. Using my Matlab m-file, "loadtransmiss" (Appendix A), data were then loaded into Matlab, corrected and converted to find $c$ (the attenuation coefficient $\mathrm{m}^{-1}$ ) (Wetlabs 2002).

$\underline{\text { Statistical analysis }}$

\section{Tidal modulation}

I addressed two aspects of the large, nocturnal emergence events, i.e. their timing and their magnitudes. Using Excel 2002, linear regression was performed on 2001 and 2002 data, comparing the start time of nocturnal and diurnal high-density emergence events and the time of the preceding slack tide in Boothbay Harbor. The time of slack tide in Boothbay Harbor was used as a proxy for stage of the tide. The term "delay period" will be used in this paper to describe the period between the start of emergence and the previous slack tide. Time of tide, rather than tidal speed was used so as to maximize the sample size for cross-correlation (given our incomplete ADCP data set). 
The same tidal velocity occurs twice between slack tides, once as the tidal velocity is increasing and once when it is decreasing. As a result, it is difficult to develop a functional relationship between a velocity that occurs several times during a 12-h period and an emergence event that occurs only once. However, a linear regression was performed to compare tidal current speed with the "magnitude" of an emergence event.

I used $t$-tests that allow unequal variances (Systat version 10.2 SPSS Inc.

Chicago, IL) to determine if there was a difference between the timing or the magnitude of nocturnal and diurnal emergence events. Two nested ANOVAs were also performed using Systat. This test was used to examine the effect of time period (night or day) and type of previous slack tide (low or high) upon the magnitude of an emergence event and the time of tide at which it occurs. To test the assumptions underlying ANOVA, a Lillefors test on residuals from treatment means assured that the resultant distribution was not significantly different from a normal one.

Time-series analysis (Chatfield 1975) was performed on ADCP and biovolume data from 1-22 August 2002. The Matlab m-file, xcov, with the "coeff" parameter selected was used for this analysis. Xcov subtracts the mean from a data set and then calculates the correlation coefficients for observations at various lags (Mathworks, 1998). Autocorrelations were performed on two series: the magnitude of the tidal current in the depth bin $2 \mathrm{~m}$ above TAPS and the sum of the biovolume from the depth bins $2-5 \mathrm{~m}$ above TAPS. To look for similarities in the temporal patterns of biovolume abundance and tidal velocity, a cross-correlation was also performed. 


\section{Trap samples}

Using samples collected over three nights, the number of animals of each species and developmental stage that were captured in the first part of the night was compared to the number caught in the second part of the night. A Lillefors test on square-roottransformed data assessed whether catches within treatments were normally distributed. In this case, the two treatments are the two parts of the night and the three different nights. If the requirements were met, nested ANOVAs were performed.

\section{RESULTS AND DISCUSSION}

\section{General emergence patterns}

The emergence pattern observed acoustically in the Damariscotta estuary site does not follow previously documented patterns. In Puget Sound, acoustic studies similar to this one (Kringel et al. 2003; Self et al., unpublished) document backscatter increasing at dusk, remaining high during the darkened hours, then terminating before dawn. The backscatter increase is attributed to increased abundance of mysids. This acoustic pattern suggests that mysids in Puget Sound daily engage in primarily one, coherent daily emergence event. Net-sampling studies of hyperbenthic organisms (e.g. Saigusa et al. 2000; Oishi and Saigusa 1999) typically have found mysid species to exhibit a single nocturnal emergence that is only slightly modulated by the tide. TAPS data from the Damariscotta estuary site, however, show two nightly emergence events (e. g. Figure 1).

One emergence event, beginning shortly after dusk, resembles the conventionally observed pattern. However, a second, usually stronger event occurs at a fixed tidal phase. The two emergence patterns may be in or out of phase depending upon the time of sunset and the tidal cycle. In this paper, unless otherwise designated, the term "emergence 
Total Nocturnal Biovolume (19 August 2002)

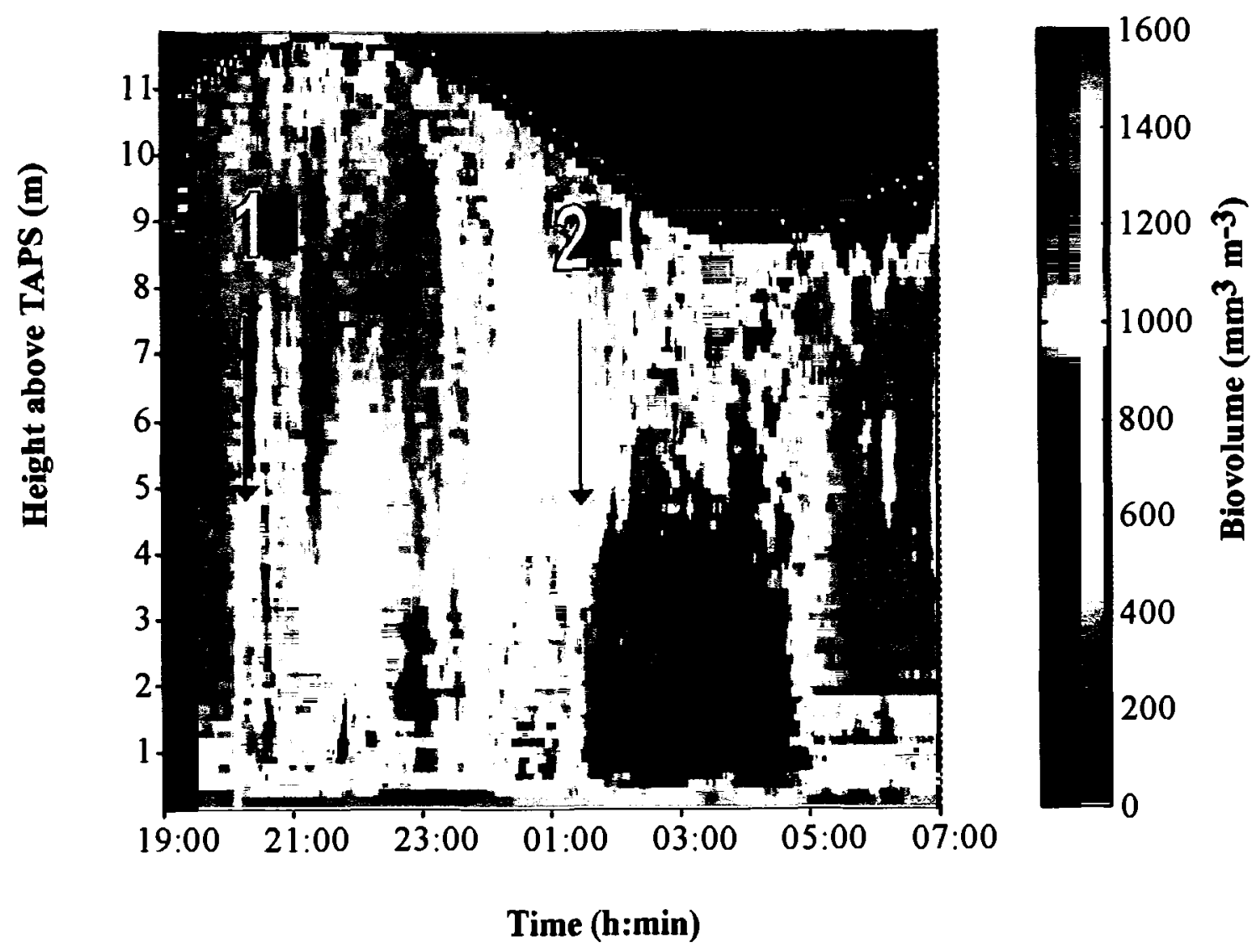

Figure 1. The pattern of biovolume shows that there are multiple emergence events on 19 August 2002. The first increase in biovolume (1) is around sunsest. Another high-density emergence event (2) occurs shortly after the highest tidal velocity. The second event is the "emergence event" found by my algorithm and is the feature that is the focus of this paper. 
event" will refer to the second, high-density event. Another acoustically observed phenomenon that is unusual in the Damariscotta estuary is a regular increase in backscatter during the day. These "daytime emergences" occur at a similar tidal phase as nocturnal emergence events (Figure 2).

\section{Comparison of "delay periods"}

A $t$-test admitting unequal variances showed a suggestive but not statistically significant difference in the "delay period" between daytime and nighttime emergence events (using separate variances $P=0.071)$, with a slightly longer delay at night (mean $=$ $3 \mathrm{~h} 46 \mathrm{~min}$ ) than during the day (mean $=3 \mathrm{~h} 3 \mathrm{~min}$ ) (Figure 3). Unfortunately, the delay periods during the day do not meet the Lillefors assumption of normality (Tcalc $=0.44$, Tcrit $=0.177)$. However, delay periods of emergences occurring on daytime incoming tides do meet the assumption of normality $(\mathrm{Tcalc}=0.051$, Tcrit $=0.252$ ), as do delay periods of emergences occurring at night on incoming tides $(\mathrm{Tcalc}=0.040$, Tcrit $=0.262)$ and delay periods of nighttime emergences on outgoing tides $(\mathrm{Tcalc}=0.08$, Tcrit $=0.90$ ). A comparison of daytime and nighttime delay periods grouped by type of tide still shows an inconclusive difference (incoming tides $P=0.089$, outgoing tides $P=0.68$ ) between the lags of day and night (Figure 4). The result of a Kruskal-Wallis test, which is the nonparametric analog to a $t$-test, provided more (but again marginally significant) support for the hypothesis that the delay period of nighttime emergences is longer than that for daytime emergences $(\mathrm{P}=0.052)$.

If the delay periods are different between day and night, it suggests that perhaps the source of the acoustic signal is also different between day and night. 
Total Daytime Biovolume (10 August 2002)

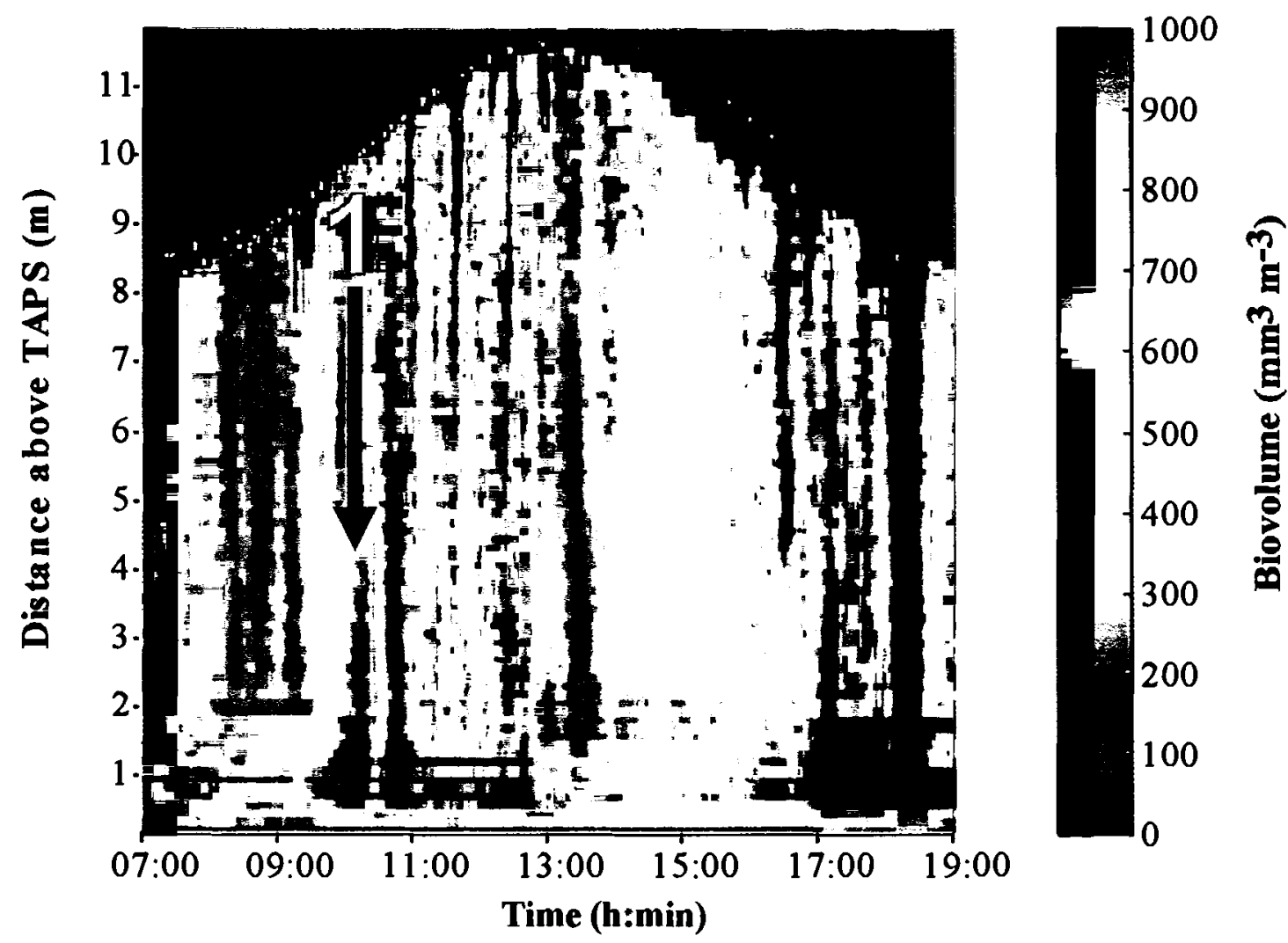

Figure 2. Application of the emergence algorithm to the day detects an increase in backscatter (1) at mid tide. The magnitude of emergence events that occur during the day is much smaller than the magnitude of nocturnal emergence events. 
Delay Period for Daytime and Nighttime Emergence Events

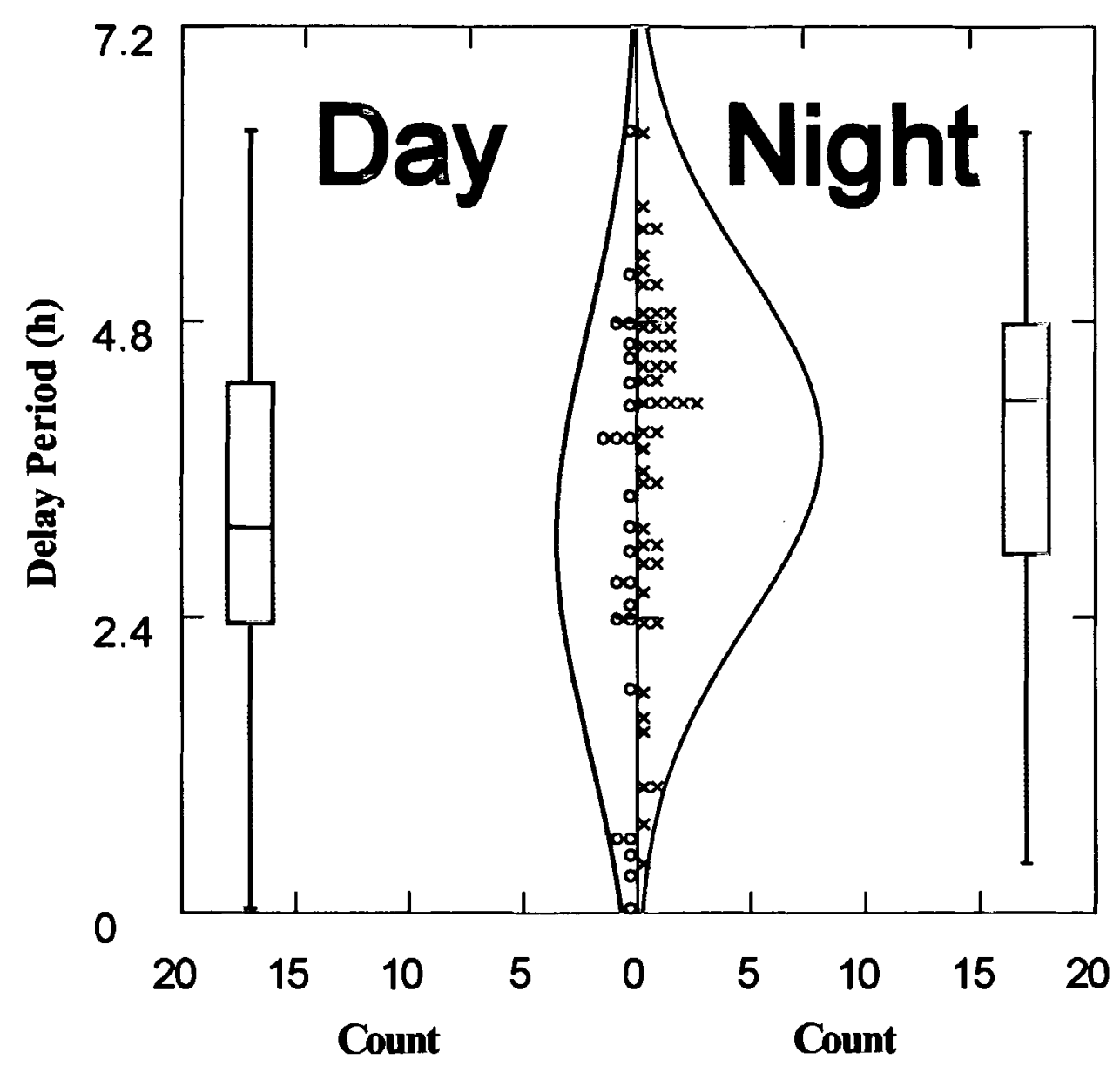

Figure 3. Although there is no statistically significant difference between mean "delay periods" in nocturnal and diurnal emergence events, there is a trend $(P=0.07)$ toward a longer delay at night $(3 \mathrm{~h} 46 \mathrm{~min})$ than during the day $(3 \mathrm{~h} 3 \mathrm{~min})$. Boxes show the spans of the central two quartiles and the medians (lines across the boxes) and whiskers the full range of observations. The curves are normal distributions fitted to the data, with magnitude on the frequency axis proportional to the number of observations. 
Delay Period for Daytime and Nighttime

Emergence Events Grouped by Type of Tide
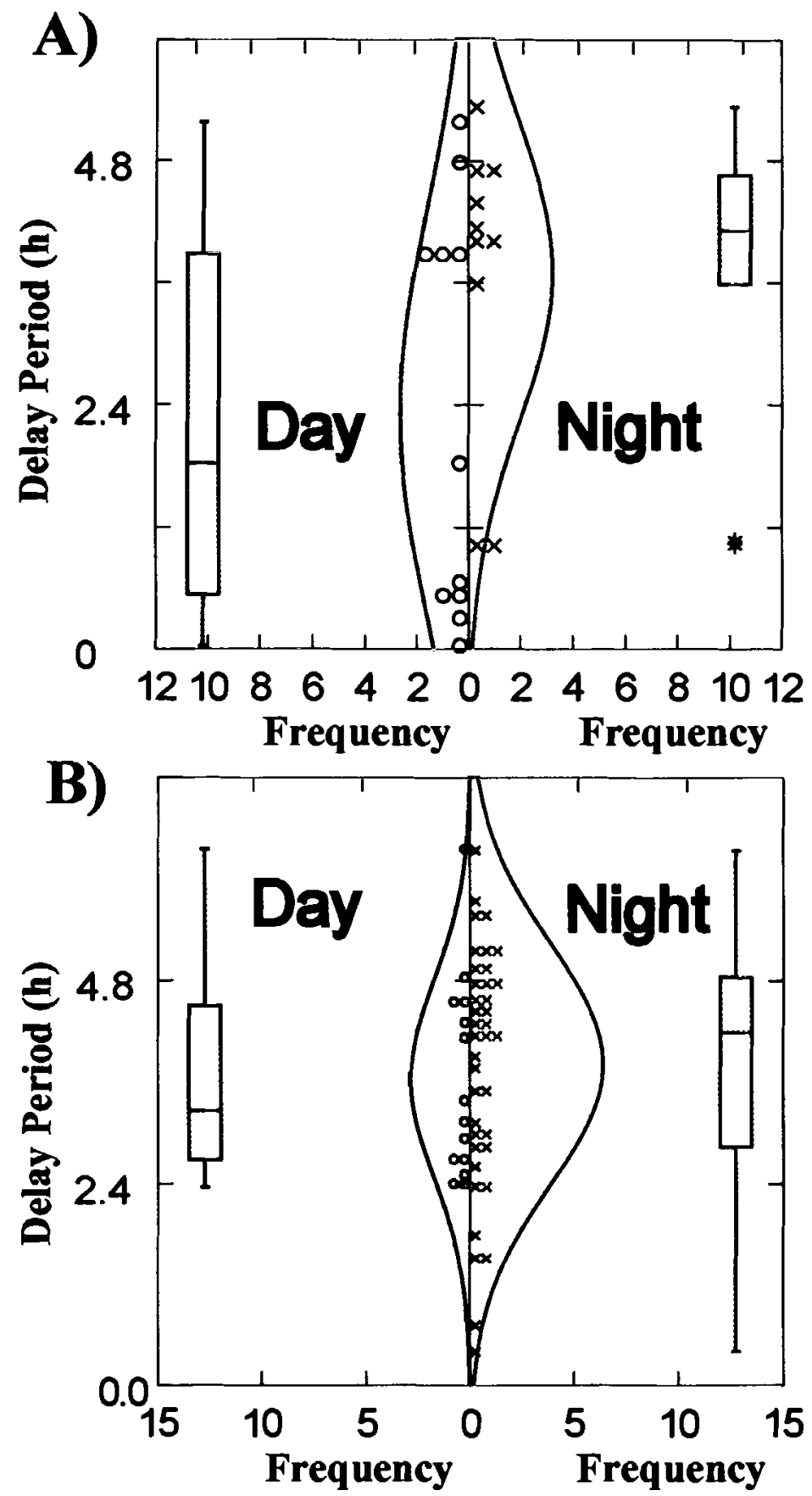

Figure 4. A) There is no statistically significant difference in delay times during incoming tides during the day versus during the night $(P=0.89)$, but the sample size is quite small. B) Although it falls short of statistical significance, there is a trend $(P=0.068)$ toward longer delays at night on outgoing tides. Boxes show the spans of the central two quartiles and the medians (lines across the boxes) and whiskers the full range of observations. The curves are normal distributions fitted to the data, with magnitude on the frequency axis proportional to the number of observations. 
Diurnal and nocturnal emergence events occurred on both incoming and outgoing tides. However, more than twice as many emergence events (day and night) were observed on outgoing tides $(\mathrm{N}=52)$ than incoming tides $(\mathrm{N}=21)$. Many more nocturnal emergence events were observed on outgoing $(N=38)$ than on incoming tidal cycles $(\mathrm{N}=10)$. A $t$-test, although not statistically significant, suggested that the delay period for events occurring on an outgoing tide (mean $=3 \mathrm{~h} 36 \mathrm{~min}$ ) was longer than for events occurring on an incoming tide (mean $=2 \mathrm{~h} 58 \mathrm{~min})(\mathrm{P}=0.089)$ (Figure 5). However, because the delay lag for daytime outgoing tides does not pass the Lillefors test, a comparison of the delay periods for emergences of incoming and outgoing tides grouped by time of day was performed (Figure 6). There is no statistically significant difference between the lag period of emergence at incoming and outgoing tides during the night $(\mathrm{P}=$ 0.83). However, during the day, there may be a difference in the delay period for emergences occurring on incoming versus outgoing tides $(P=0.070)$. A Kruskal-Wallis test found no significant difference $(P=0.147)$ between the delay lags of emergences occurring on incoming versus outgoing tides.

\section{Comparison of emergence magnitudes}

A $t$-test (that allowed different variances) did show a significant difference between the magnitudes of nocturnal and diurnal emergence events $P=3.6 \times 10^{-12}$ ). The mean magnitude (threshold value used in the algorithm) of diurnal emergence is $465 \mathrm{~mm}^{3}$ $\mathrm{m}^{-3}$ and of nocturnal emergence is $955 \mathrm{~mm}^{3} \mathrm{~m}^{-3}$ (Figure 7). However, the magnitudes at night did not meet the assumption of normality $(\mathrm{Tcalc}=1$, Tcrit $=0.165)$. A Kruskal- 
Delay Period for Emergence Events Occuring on Incoming and Outgoing Tides

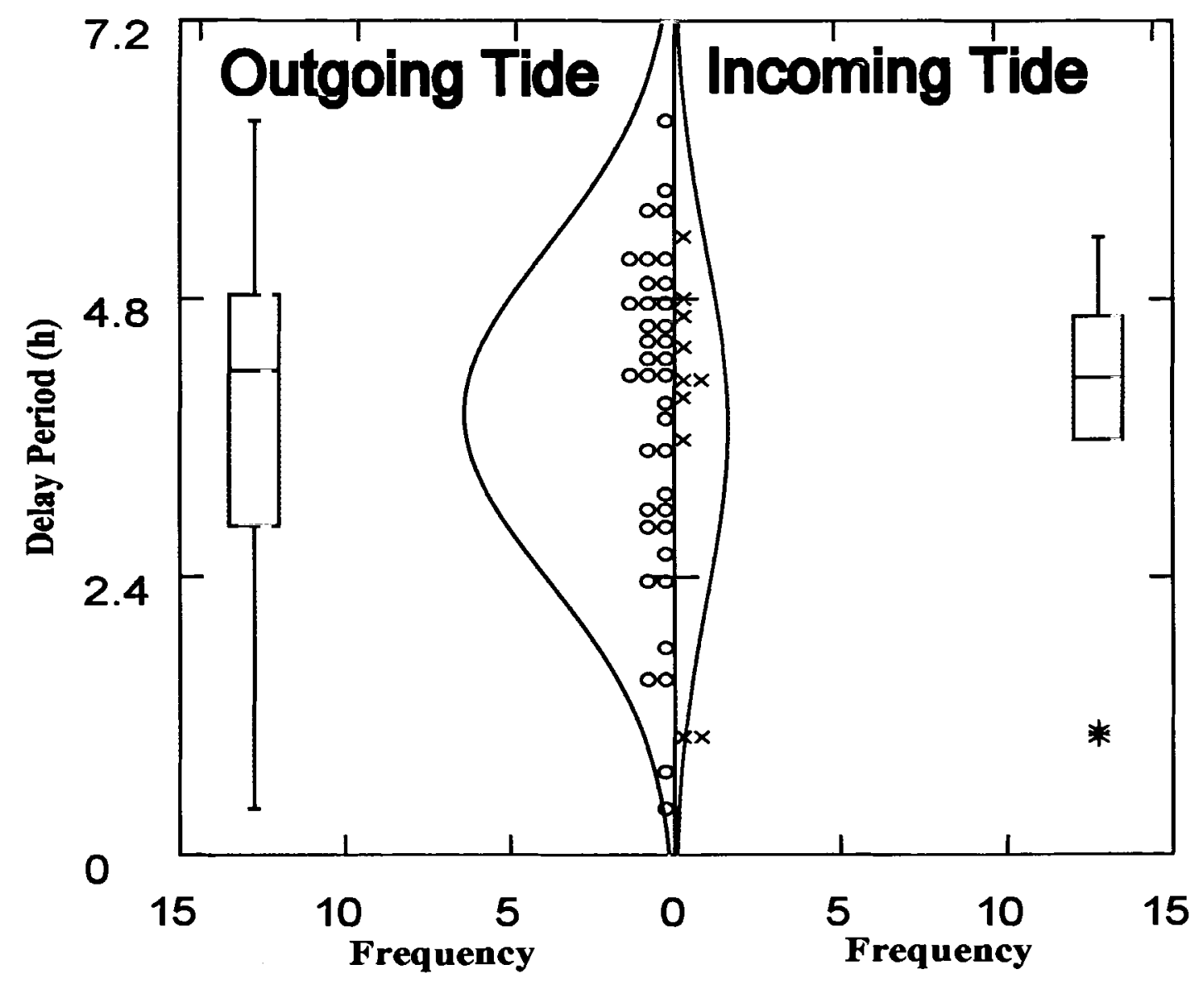

Figure 5. Although there is a trend toward longer delays on outgoing than incoming tide $(P=0.089)$, it is not statistically significant and may in part be due to interaction of day and night differences with these tidal differences (see text). Boxes show the spans of the central two quartiles and the medians (lines across the boxes) and whiskers the full range of observations. The curves are normal distributions fitted to the data, with magnitude on the frequency axis proportional to the number of observations. 
Delay Period for Emergence Events Occuring on Incoming and Outgoing Tides Grouped by Time of Day (Day/Night)
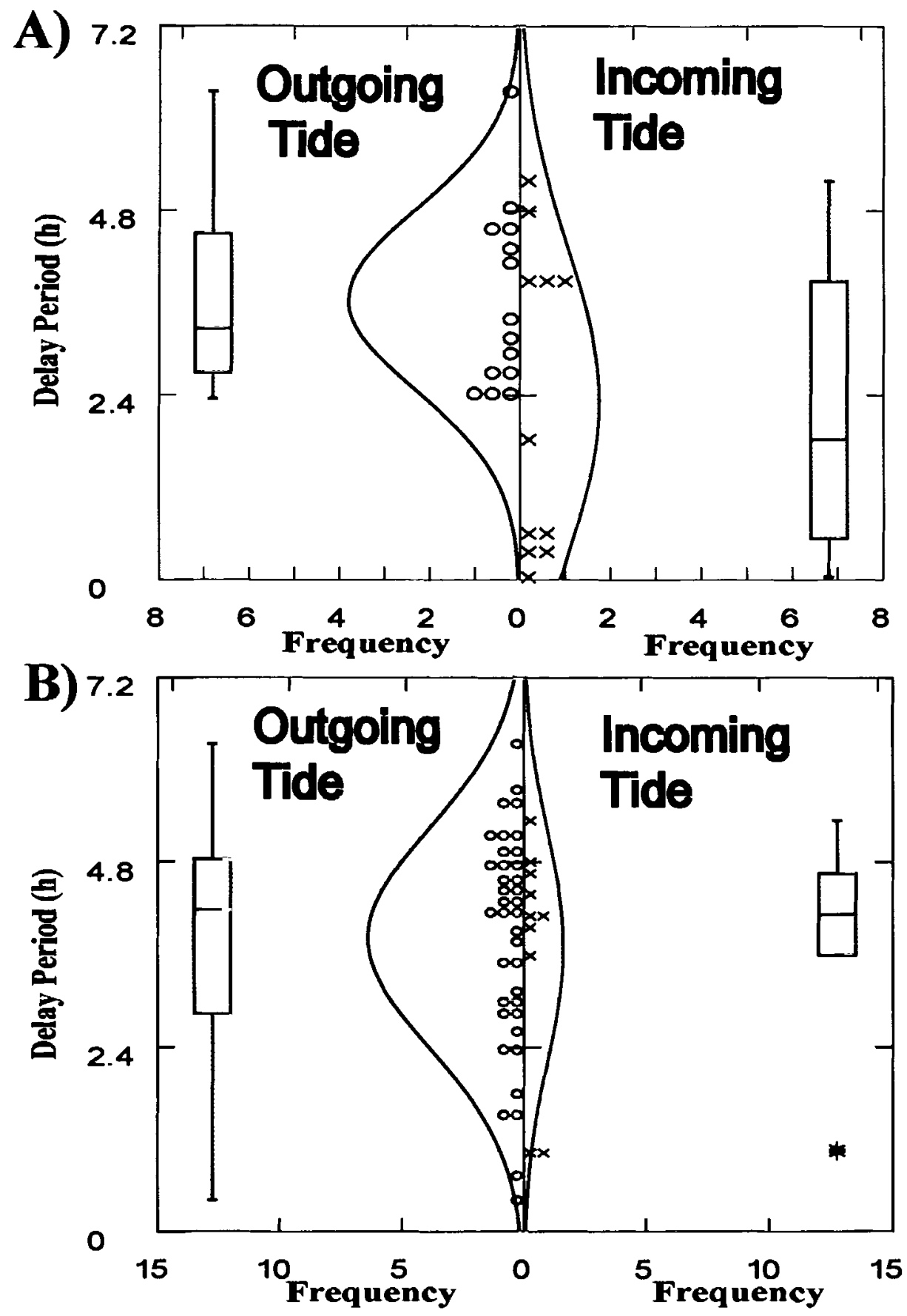

Figure 6. A) Although the differences are not statistically significant, emergence events tend to show slightly longer lags on outgoing than on incoming tides both (A) during the day $(\mathrm{P}=0.083)$ and $(\mathrm{B})$ at night $(\mathrm{P}=0.07)$. Boxes show the spans of the central two quartiles and the medians (lines across the boxes) and whiskers the full range of observations. The curves are normal distributions fitted to the data, with magnitude on the frequency axis proportional to the number of observations. 
Magnitude of Daytime and Nighttime Emergence Events

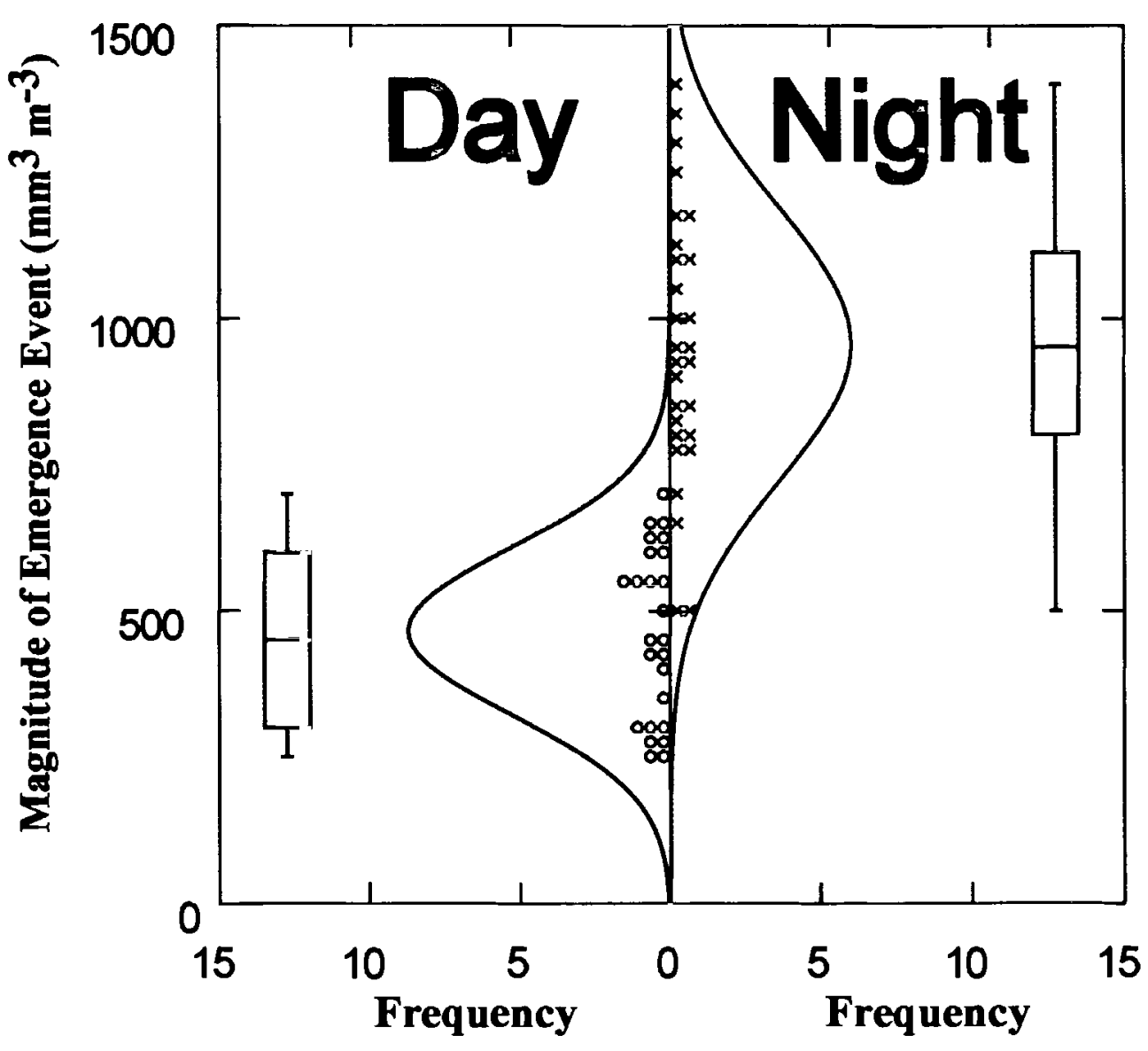

Figure 7. There is a significant difference between the mean value of the threshold biovolume found by the emergence algorithm during the day versus during the night, with the nighttime value being over twice as high $\left(P=3.6 \times 10^{\wedge}-12\right)$. Boxes show the spans of the central two quartiles and the medians (lines across the boxes) and whiskers the full range of observations. The curves are normal distributions fitted to the data, with magnitude on the frequency axis proportional to the number of observations. 
Wallis test found a significant difference between the magnitude of daytime emergence versus nighttime emergence $\left(P=7.1 \times 10^{-9}\right)$.

The type of tide (outgoing or incoming) did not have a significant effect on the magnitude of an emergence event $(P=0.717)$. However, the magnitudes of emergences on incoming tides were not normally distributed (Lillefors Tcalc $=0.96$, Tcrit $=0.201$ ). A comparison of incoming and outgoing tidal emergence magnitudes grouped by time of day showed no difference between the magnitudes of emergences on incoming versus outgoing tides during the day or the night (day $\mathrm{P}=0.71$, night $\mathrm{P}=0.83$ ). A KruskalWallis test showed a suggestive but not significant difference between the magnitude of emergence on incoming versus outgoing tides $(P=0.074)$. It is possible that the magnitude of emergence on outgoing tides is greater $($ mean $=774)$ than the magnitude of emergence on incoming tides (mean $=586$ ). However, a greater percentage of nocturnal emergence events than daytime emergence events take place on an outgoing tide, and nighttime emergence events have a greater magnitude than daytime emergence events. The perceived difference between the magnitude of emergence during incoming versus outgoing tides could be a result of interaction between time of tide and time of day.

\section{Interaction effects}

The results of a nested ANOVA, a parametric statistical test, showed that the type of tide had no statistically significant influence on the effect that time of day (day/night) had on the "delay period" $(P=0.133)$. Nor did the type of tide influence the effect of time of day on the magnitude $(P=0.949)$. However, the data do not adhere to the required assumptions for an ANOVA. A nonparametric analog was performed, but it is not capable of resolving interactions. 


\section{Tidal modulation}

There is a strong linear relationship between the estimated time of slack tide in Boothbay Harbor and the initiation time of the high-density emergence event. This relationship can be seen in data collected in both $2002\left(R^{2}=0.84\right)$ (Figure 8) and 2001 $\left(R^{2}=0.81\right)$ (Figure 9). Diurnal emergence events also share this relationship $\left(R^{2}=0.80\right)$ (Figure 10). The linear relationship also holds true when nocturnal and diurnal emergence events are pooled $\left(R^{2}=0.94\right)$ (Figure 11).

The average time between slack tide in Boothbay Harbor and an emergence event observed by TAPS is $3 \mathrm{~h} 31 \mathrm{~min}$. The delay between slack tide in Boothbay Harbor and slack tide near TAPS is approximately 15-20 min. Therefore, the "delay period" between local slack tide and local emergence is 3.7 and $4 \mathrm{~h}$. Four hours after slack tide, tidal velocities begin slowing (Figure 12). Most emergence events occur during times of decreasing tidal velocities (e.g. Figure 13). That is, the emergence event begins when the local tide begins to decelerate.

Although changes in tidal speed seem to influence the initiation of emergence, there appears to be no threshold speed that triggers emergence. The tidal speed at the time of emergence varies widely (Figure 14). The tidal speed at which a high-density emergence event begins also varies widely. The mean speed is $14.6 \mathrm{~cm} \mathrm{~s}^{-1}$ with a standard deviation of 47. Even taking nocturnal and diurnal emergence events during incoming or outgoing tides separately, the speed at the time emergence begins varies substantially (Figure 15). A histogram of tidal speeds for 1-17 August 2002 shows that $14.6 \mathrm{~cm} \mathrm{~s}^{-1}$ (the average tidal speed at the start of an emergence event) is a very common 
Tidal Modulation of a Nocturnal Emergence Event (July - September 2002)

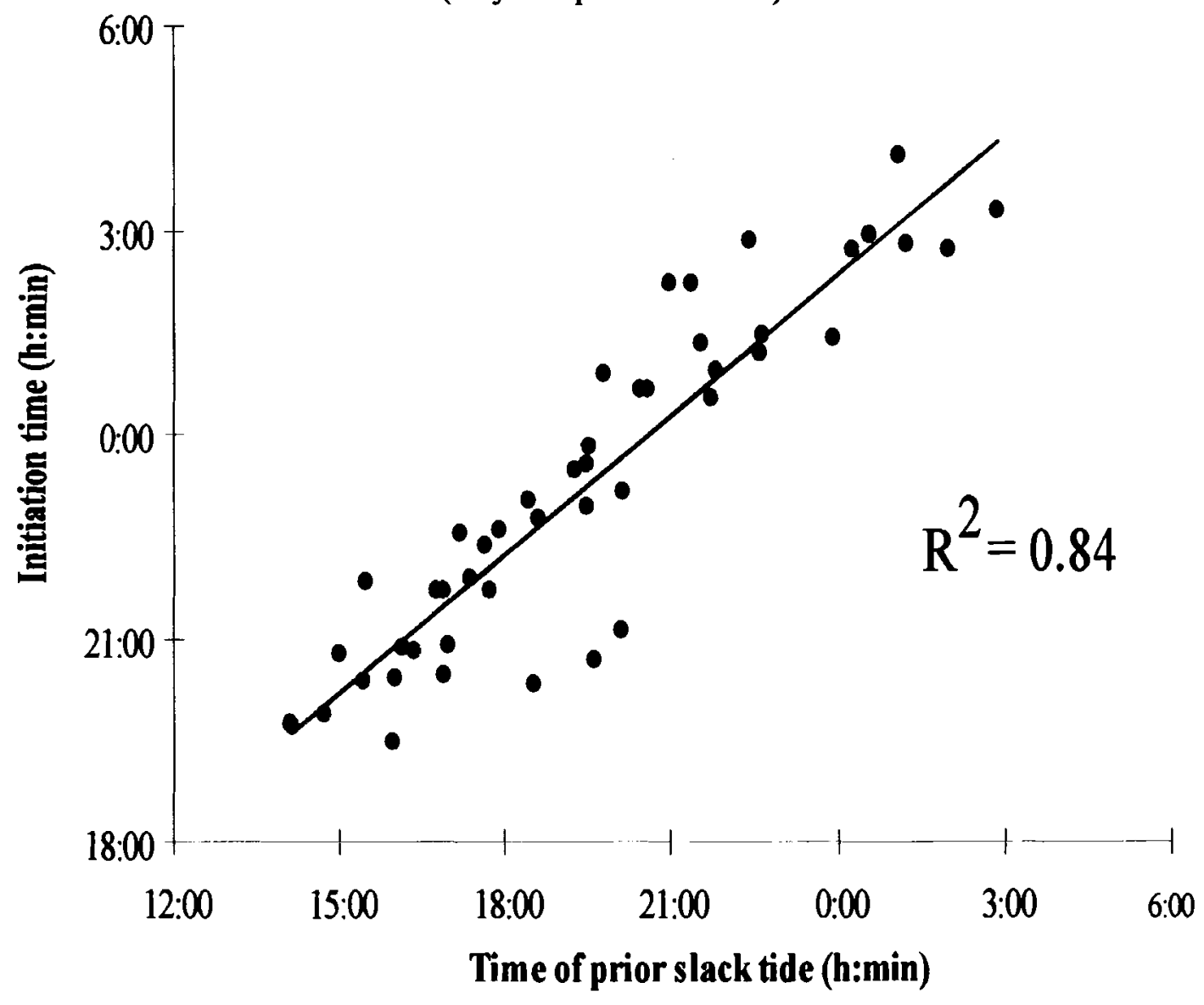

Figure 8. For nocturnal observations in 2002 , there is a significant linear relationship between the time of slack tide in Boothbay Harbor, which is a proxy for phase of the tide, and the initiation time of a high-density emergence event. 
Tidal Modulation of a Nocturnal Emergence Event

(August and September 2001)

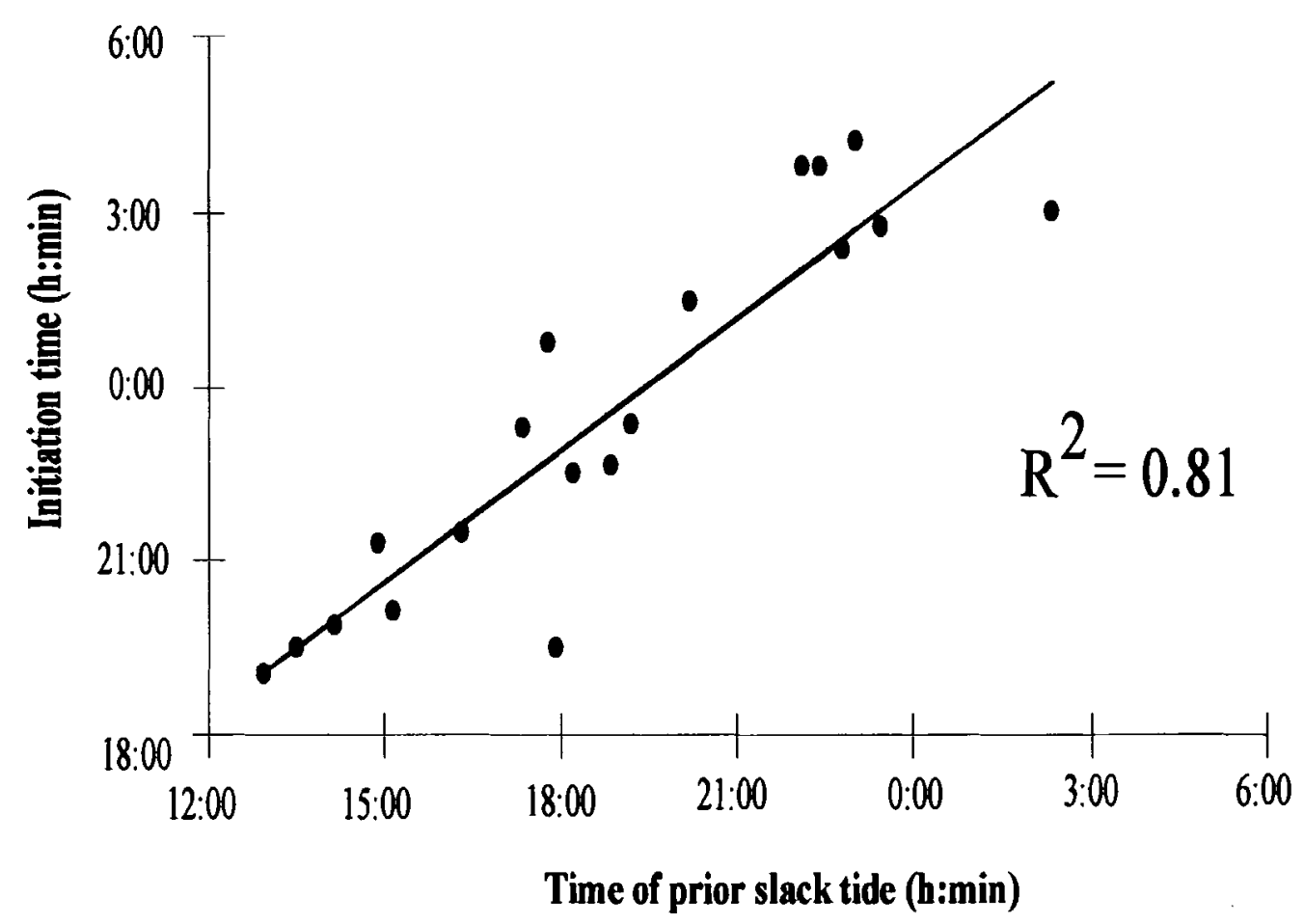

Figure 9. For nocturnal observations in 2001, there is a significant linear relationship between the estimate of time of slack tide in Boothbay Harbor, which is a proxy for phase of the tide, and the initiation time of a high-density emergence event. 


\section{Tidal Modulation of a Diurnal Emergence Event}

(August 2002)
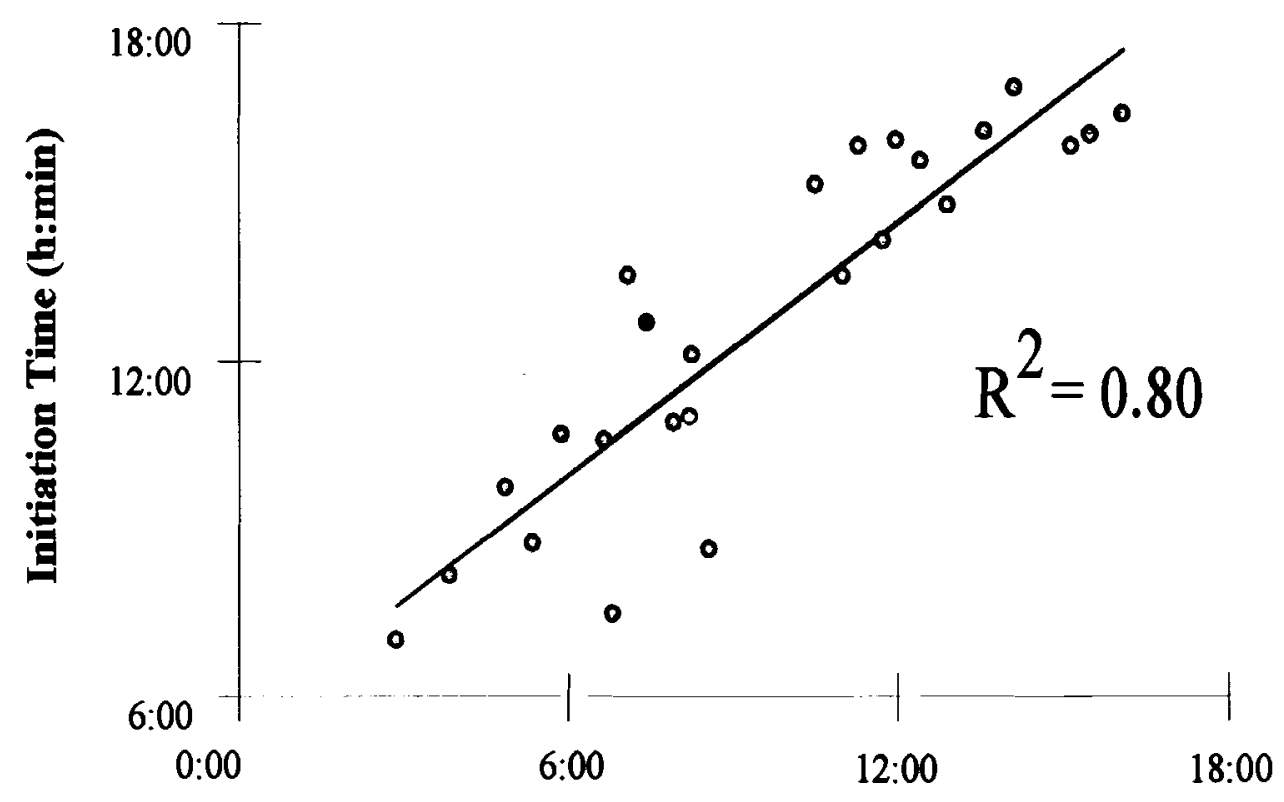

Time of prior slack tide (h:min)

Figure 10. For diurnal observations in 2002, there is a significant linear relationship between the time of slack tide in Boothbay Harbor, which is a proxy for phase of the tide, and the initiation time of a high-density emergence event. 
Tidal Modulation of Diumal and Nocturnal Emergence Events

(August 2002)

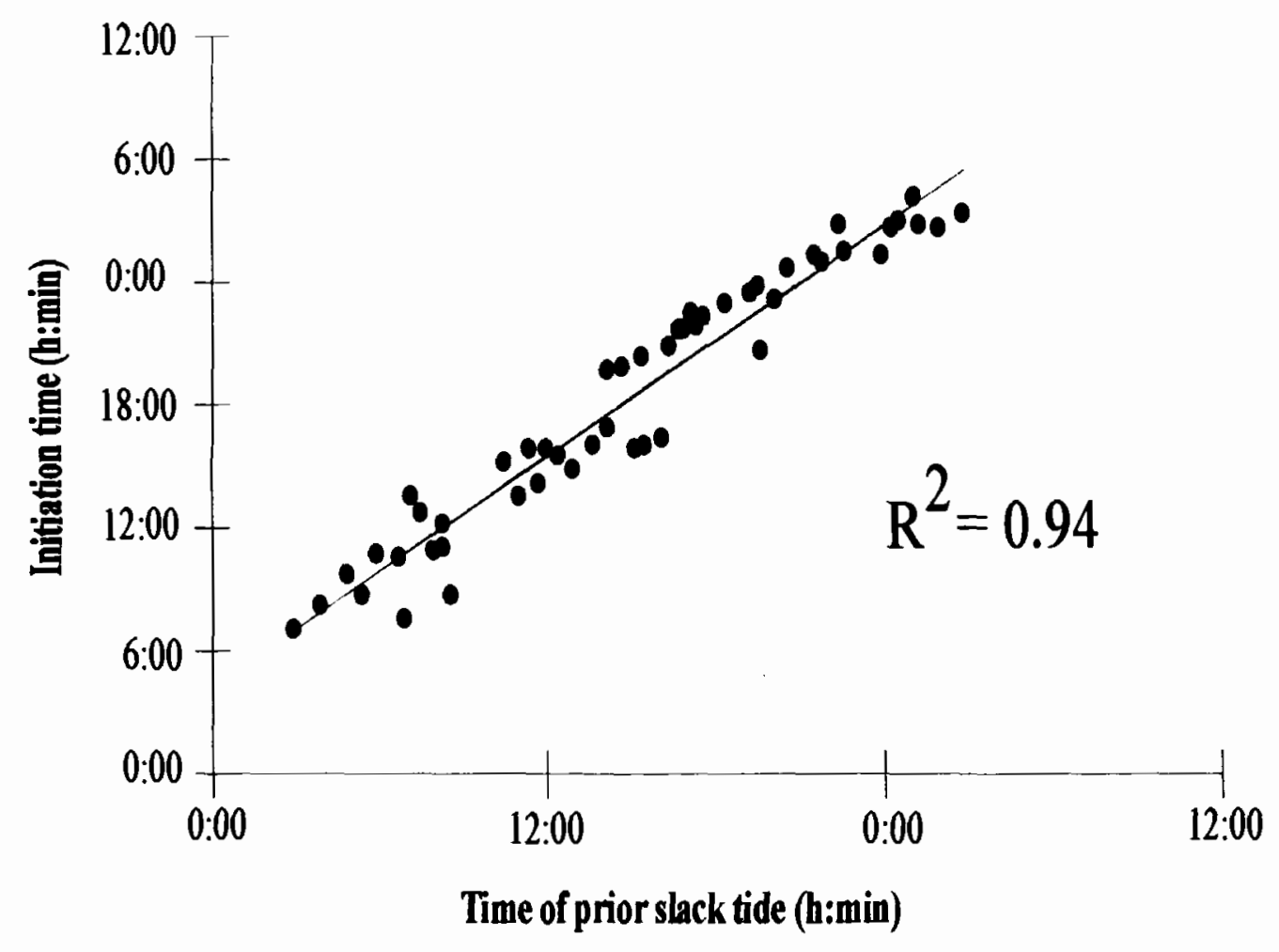

Figure 11. For both diurnal and nocturnal observations in August 2002, there is a significant linear relationship between the time of slack tide in Boothbay Harbor, which is a proxy for phase of the tide, and the initiation time of a high-density emergence event. 
Local Tidal Speed $0.1 \mathrm{~m}$ above the Bottom Subsequent to High Tide in Boothbay Harbor

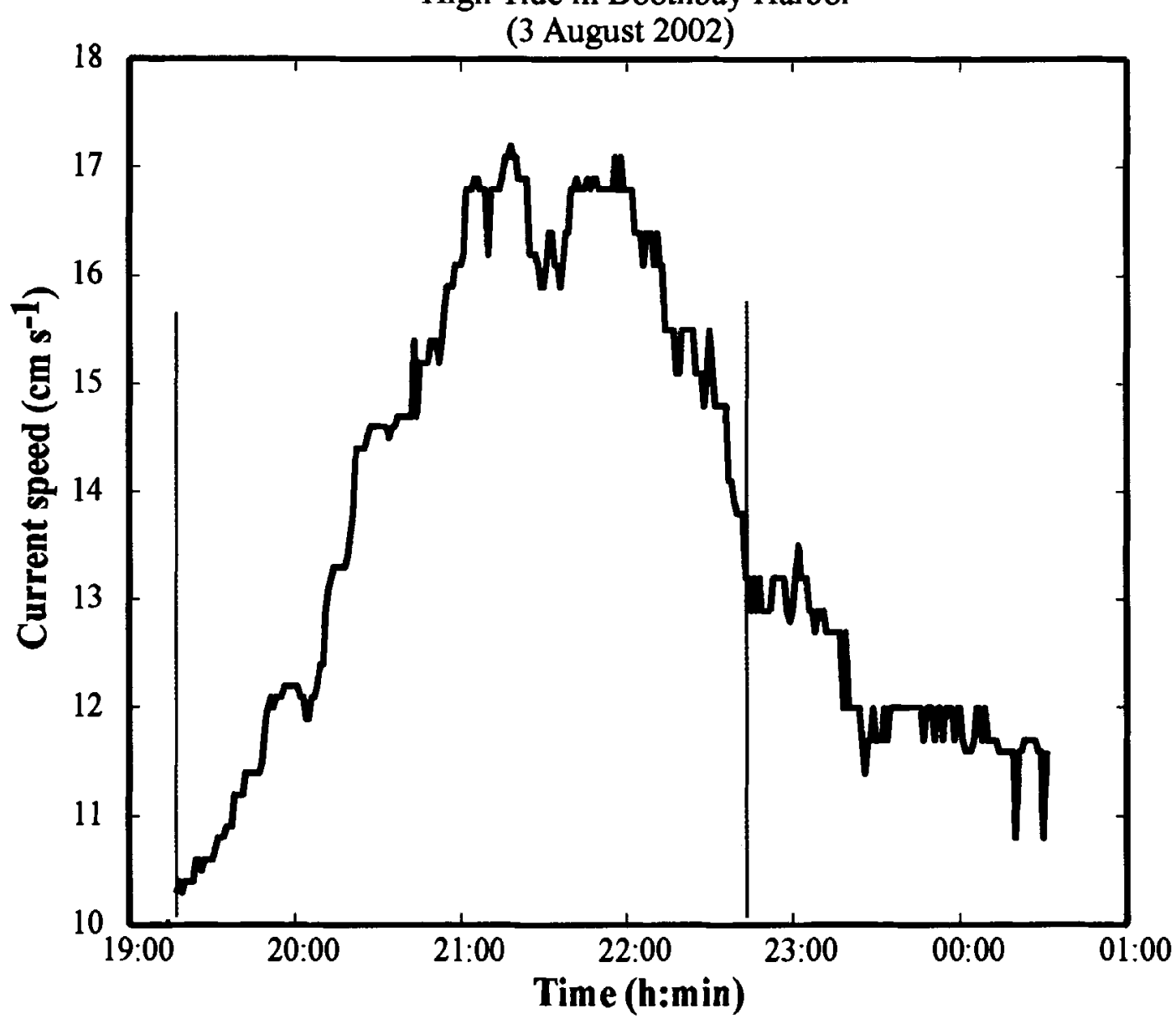

Figure 12. ADCP record of tidal velocities at our study site, $0.1 \mathrm{~m}$ above the seabed on 3 August. On this night the high-density emergence event begins roughly $3.5 \mathrm{~h}$ (red vertical line) after the estimated time of low tide at Boothbay Harbor (blue vertical line). The tidal record has been 61-point median smoothed. 
Current Speed at Initiation Time of an Emergence Event
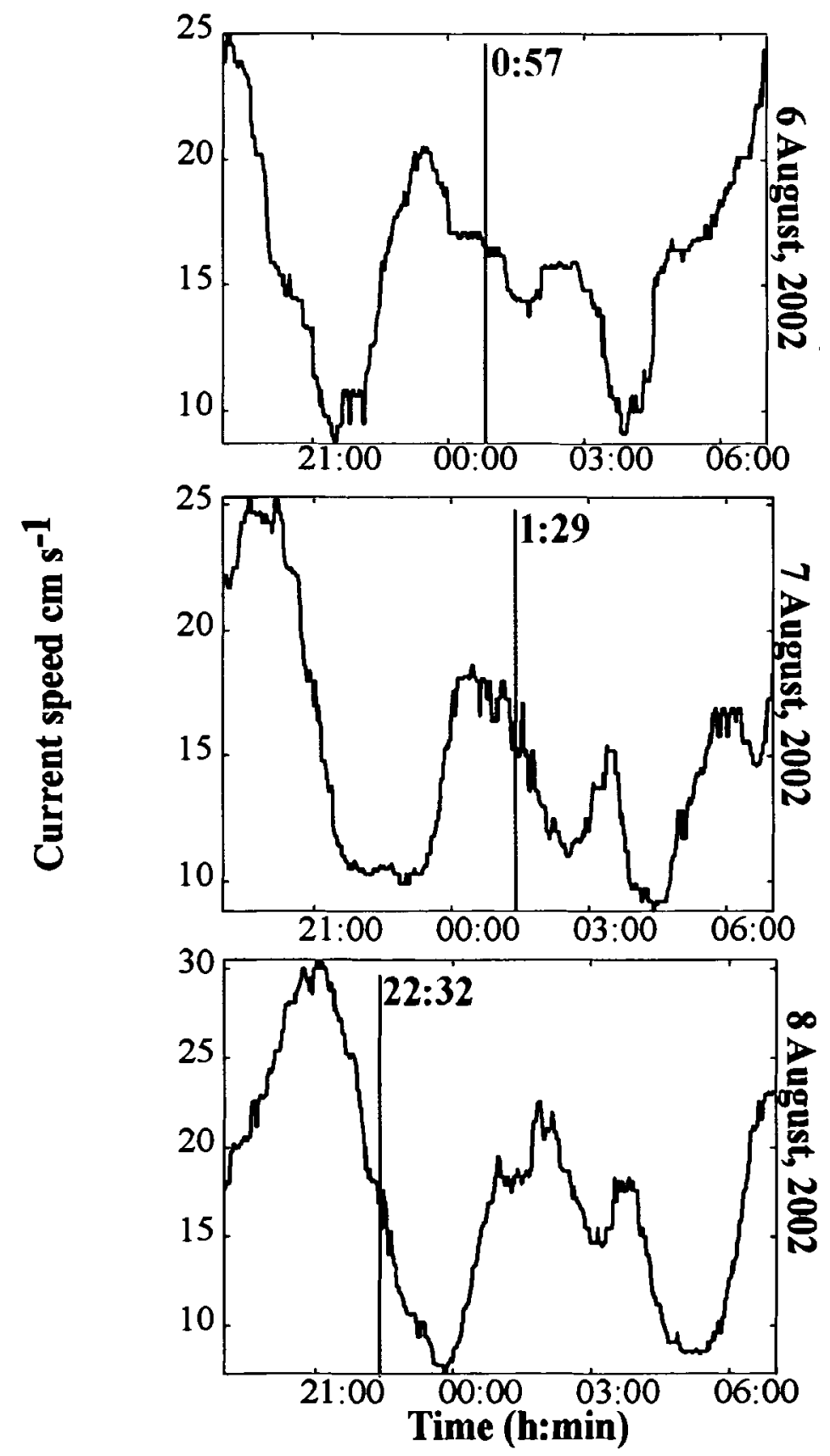

Figure 13. Many emergence events occur at times when tidal currents are decelerating. In each plot, the black line represents tidal speed measured at $0.1 \mathrm{~m}$ above the ADCP. The red vertical line is drawn at the initiation time of a high density emergence event. 
Histogram of Current Speed $0.1 \mathrm{~m}$ above the Bottom at the Initiation Times of Emergence Events

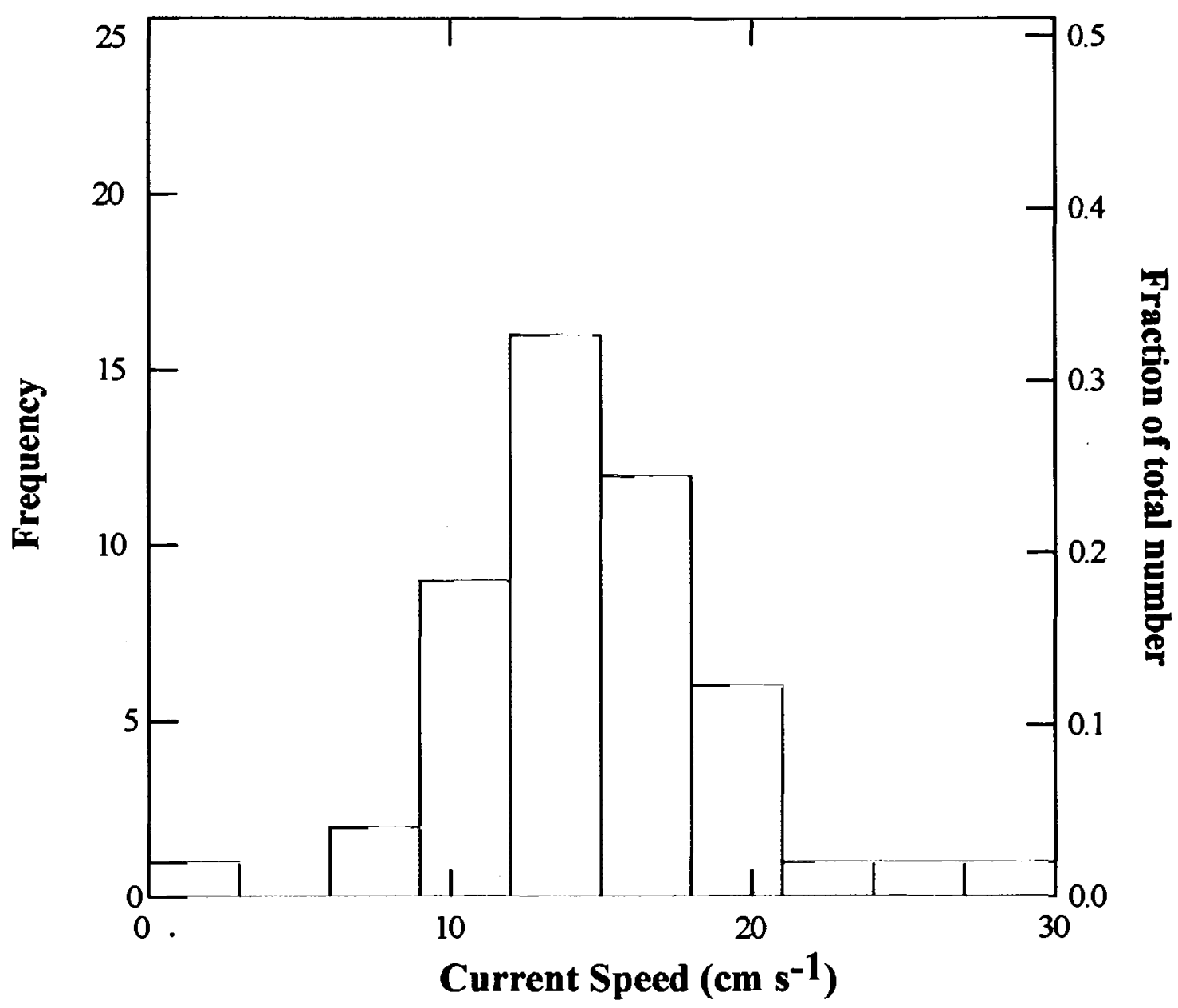

Figure 14. The tidal speed at which a high-density emergence event begins varies widely. The mean speed is $14.6 \mathrm{~cm} \mathrm{~s}^{-1}$ with a standard deviation of $4.7 \mathrm{~cm} \mathrm{~s}^{-1}$. 
Histogram of Current Speed $0.1 \mathrm{~m}$ Above the Bottom at the Initiation Times of Emergence Events Grouped by

Type of Tide and Time of Day

Day

a.

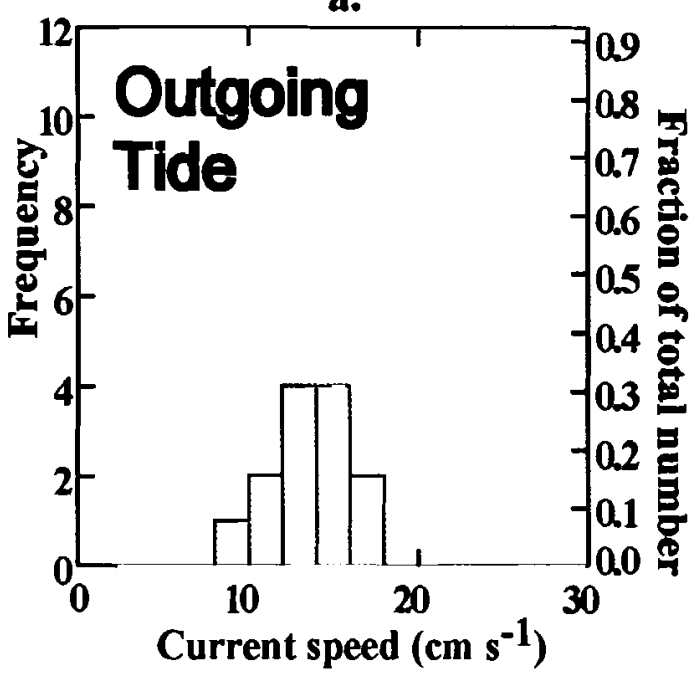

b.

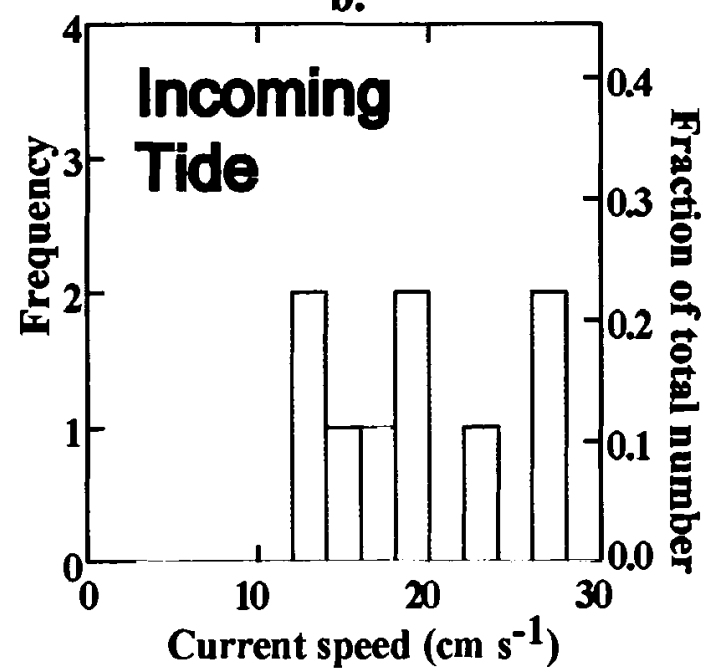

Night
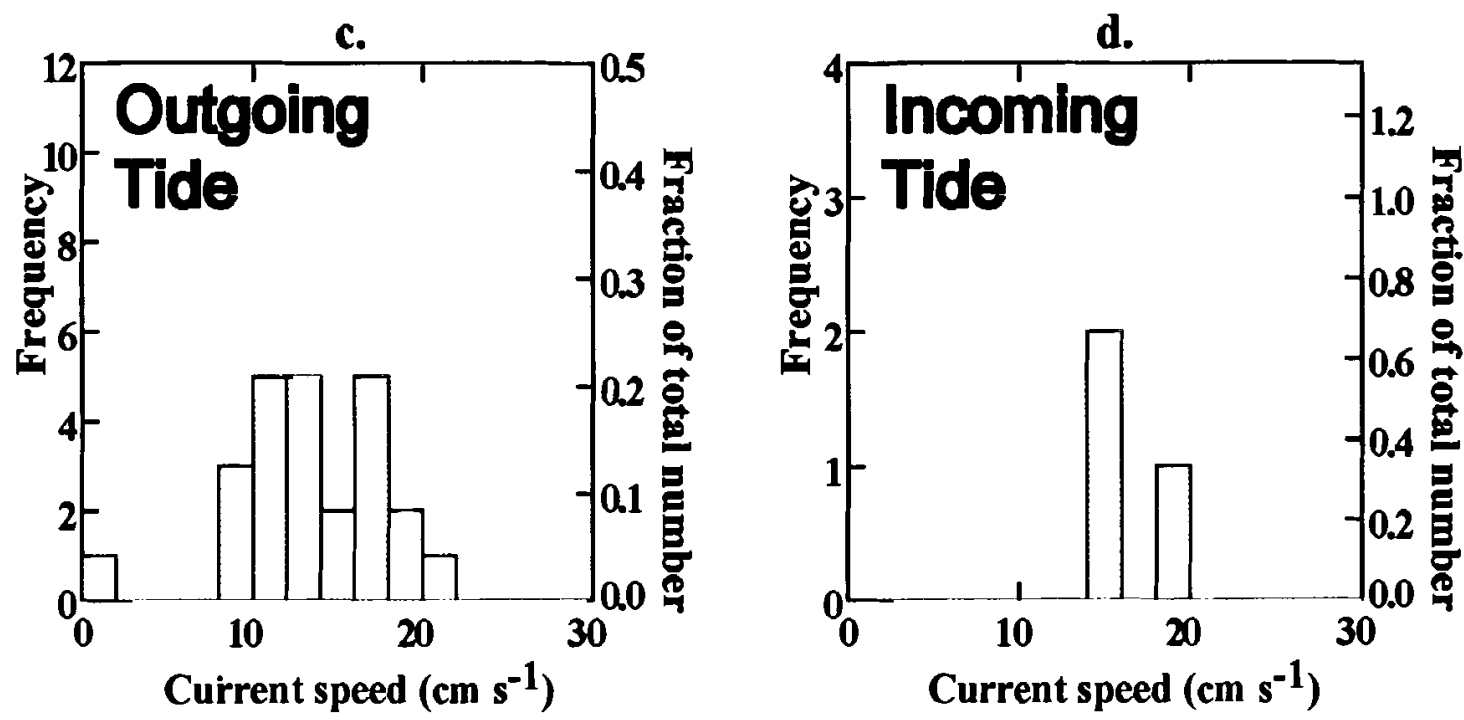

Figure 15. Even taking nocturnal and diurnal emergence events during incoming and outgoing tides separately, the tidal speed at which a high-density emergence event begins varies considerably. 
tidal velocity (Figure 16). Even so, there does appear to be a weak linear relationship between the magnitude of tidal speed and the magnitude of emergence (Figure 17). Time-series results

The autocorrelogram of total biovolume (2-5 $\mathrm{m}$ above TAPS) shows coherence over 2-h intervals (Figure 18). There is also a peak in autocorrelation at $18 \mathrm{~h}$ lag; $18 \mathrm{~h}$ is approximately the period between times with similar nocturnal tidal speeds (e.g. between a peak outgoing flow and the next night's peak incoming flow). This peak supports the hypothesis that biovolume is tidally modulated on the time scale of days. At lags between 21 and $26 \mathrm{~h}$ significant autocorrelation coefficients also are calculated. This broad peak probably reflects both a correlation with the light cycle (24-h period; Abello, in preparation) and with the tides (25.4-h period).

On a longer time scale, the autocorrelogram of total biovolume (2-5 $\mathrm{m}$ above TAPS) shows that biovolume is autocorrelated at lags of $1,2,3 \ldots \mathrm{d}(24,48,72 \ldots \mathrm{h})$ (Figure 19). The weakening of the autocorrelation at larger lags reflects a falling sample size with increasing lag. The rise in the correlation coefficent at 13-d lag reflects the period between two consecutive spring or neap tides, so it is possible that biovolume is also tidally modulated on the time scale of months. In this study, however, there are too few observations separated by lags over $15 \mathrm{~d}$ to demonstrate this relationship more conclusively.

The autocorrelogram of bottom tidal current speed near TAPS represents a system in which there are different bottom tidal speeds during incoming and outgoing tides (Figure 20). As expected, the autocorrelogram of bottom tidal speed shows strong autocorrelation at the tidal period, a little over 12 and $24 \mathrm{~h}$. At 6 and $18 \mathrm{~h}$ lag (e.g. lags 
Histogram of Tidal Speed $0.1 \mathrm{~m}$ Above the Bottom 1-17 August 2002

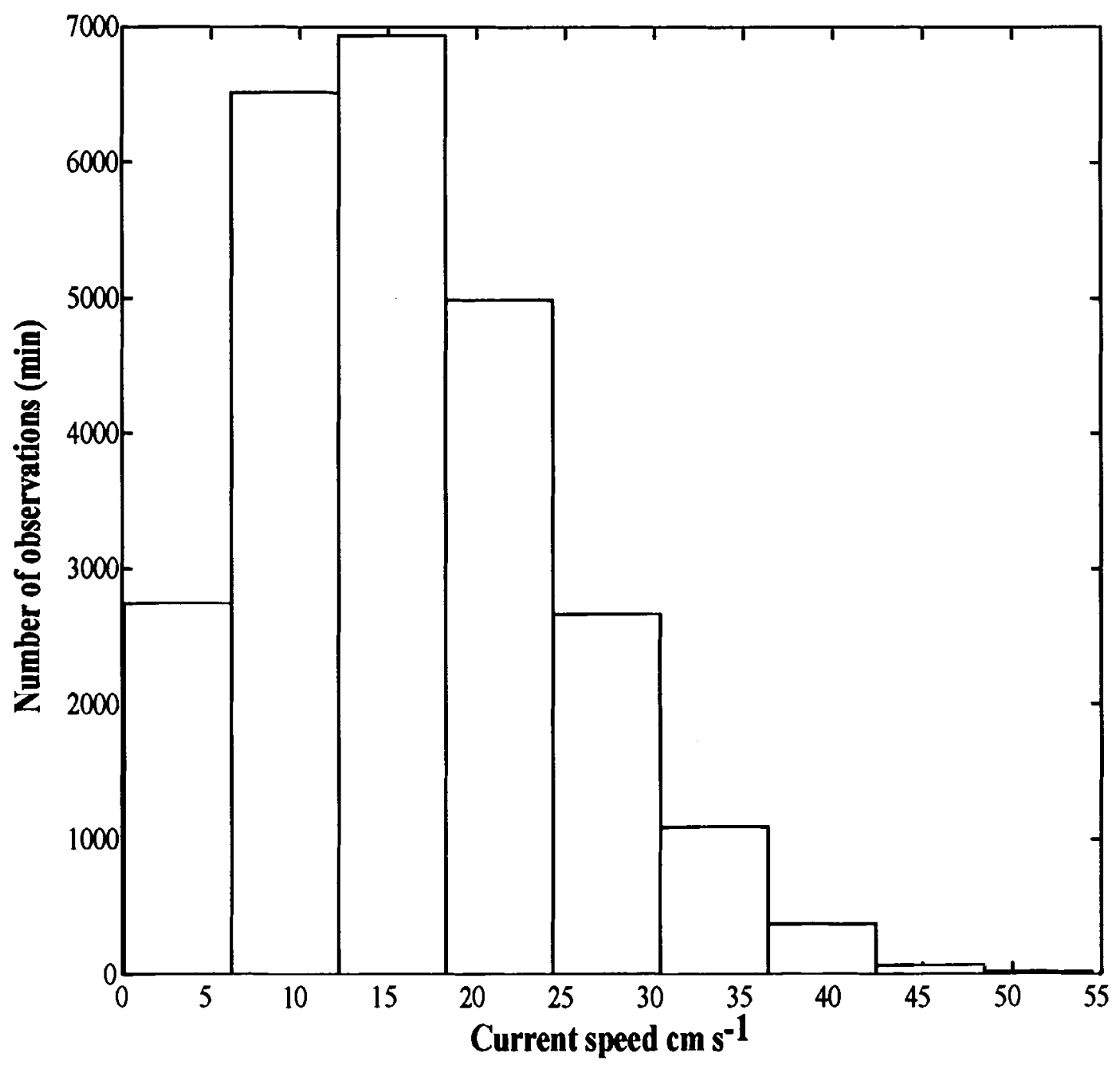

Figure 16. A histogram of current speeds for 1-17 August 2002 shows that $14.6 \mathrm{~cm} \mathrm{~s}-1$ (the average current speed at the start of an emergence event) is a very common current speed. It falls into the histogram bin with the most observations. 
The Influence of Current Speed on the Magnitude of

Emergence Events

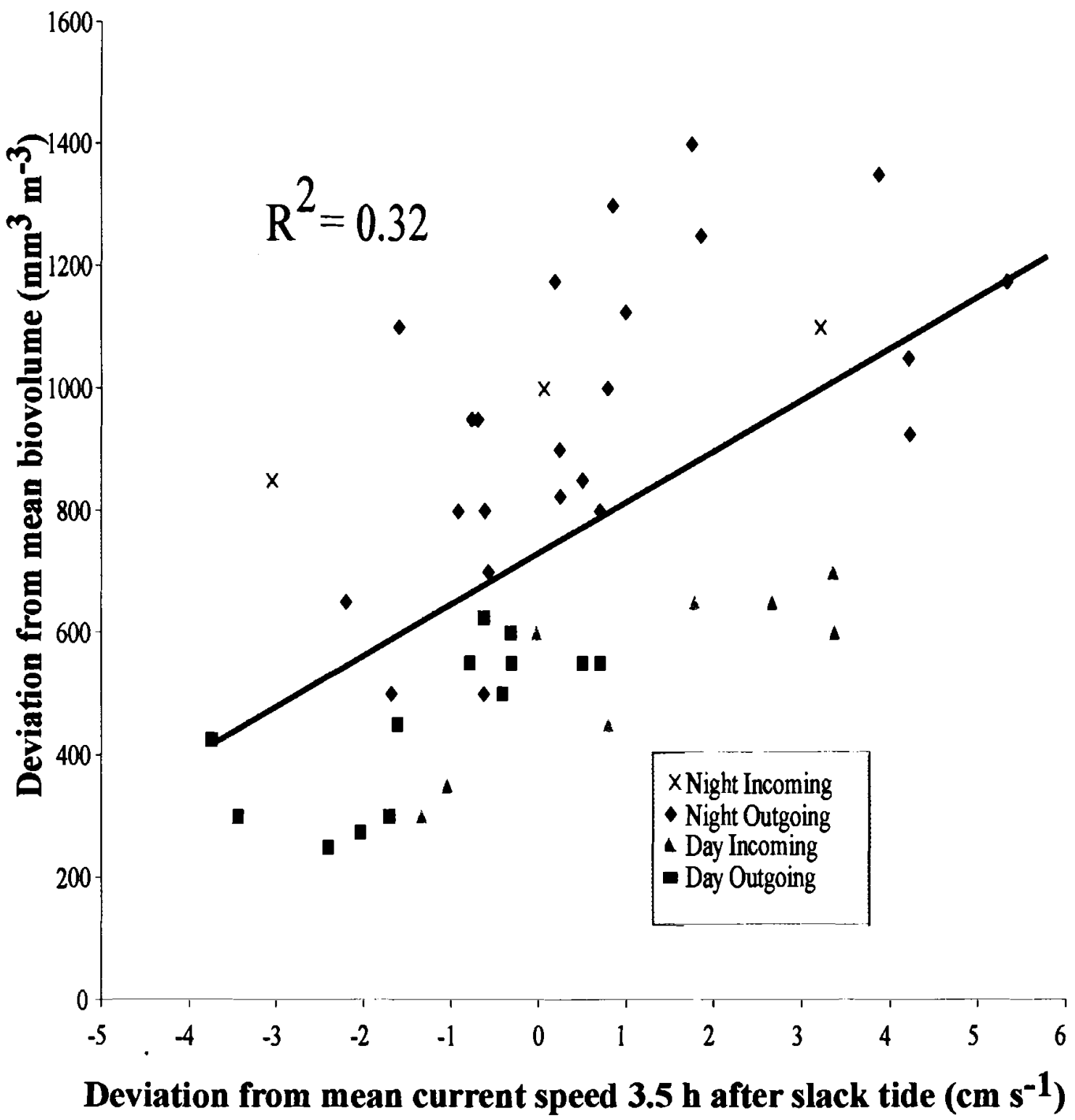

Figure 17. There is a weak, positive, linear relationship between relative tidal speed $0.1 \mathrm{~m}$ above bottom and the relative magnitude of the emergence event as measured by the threshold biovolume located by the algorithm. Relative current speed is the actual current speed $\left(\mathrm{cm} \mathrm{s}^{-1}\right)$ minus the mean current speed $3.5 \mathrm{~h}$ after slack tide (calculated separately for incoming and outgoing tides). Relative biovolume ( $\mathrm{mm} \mathrm{m}-3)$ is the threshold found by the algorithm minus the mean threshold value (calculated separatedly for daytime and nighttime events). 
Autocorrelogram of Total Biovolume on the Scale of Hours (1-28 August $2002: 2-5 \mathrm{~m}$ above TAPS)

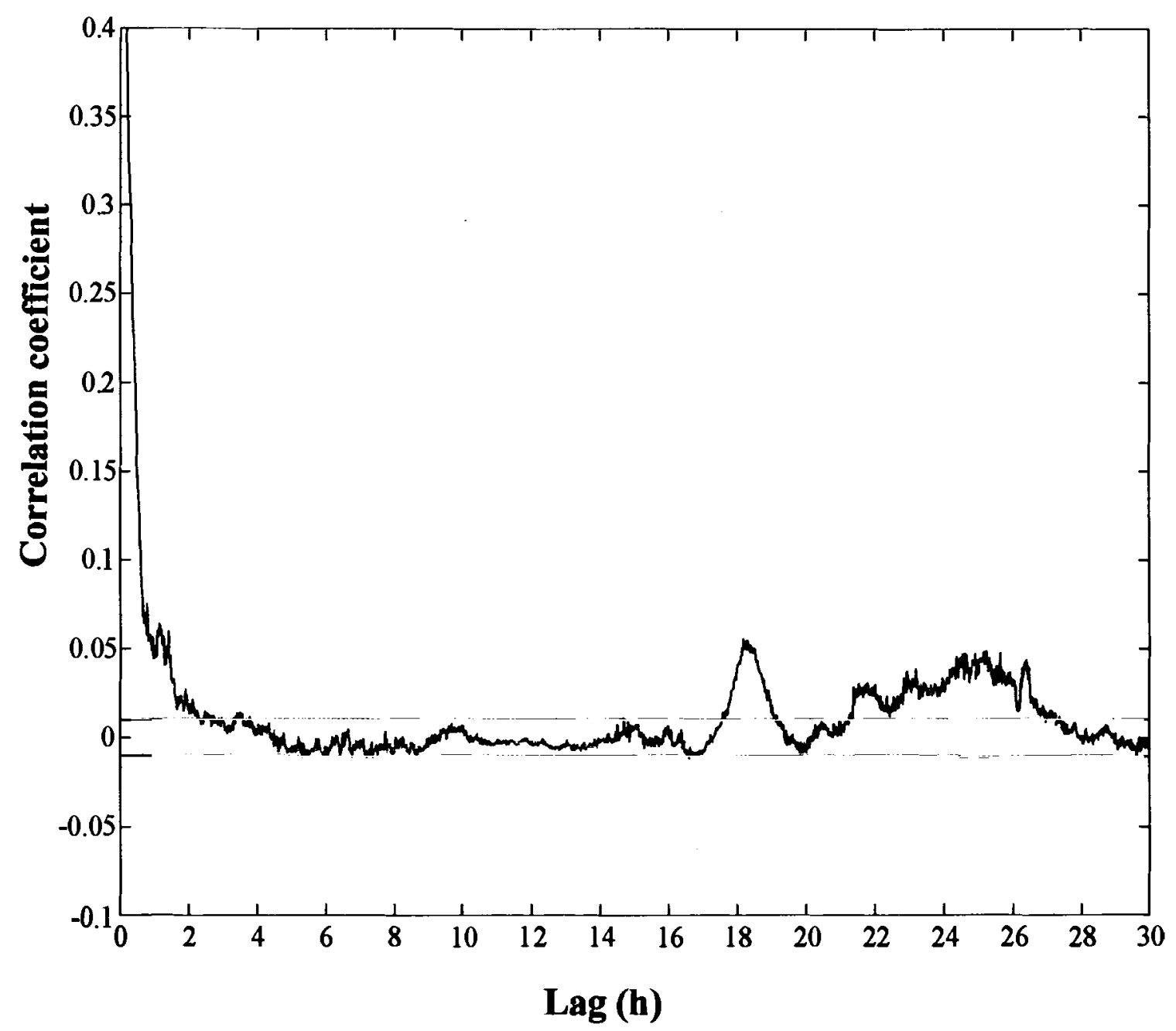

Figure 18. Autocorrelogram of total biovolume (2-5 $\mathrm{m}$ above TAPS) within $2-4 \mathrm{~h}$ are coherent. Zero lag has a correlation coefficient of one. The red lines represent confidence limits. There is also a peak in autocorrelation at $18 \mathrm{~h} \mathrm{lag;} 18 \mathrm{~h}$ is approximately the period between times with similar nocturnal tidal speeds (e.g. between a peak outgoing flow and the next night's peak incoming flow). At lags between 21 and $26 \mathrm{~h}$ significant correlation coefficients are calculated. Lags near $24 \mathrm{~h}$ are significant, suggesting a diel component to the biovolume pattern. 
Autocorrelogram of Total Biovolume on the Scale of Days

(1-28 August $2002: 2-5 \mathrm{~m}$ above TAPS)

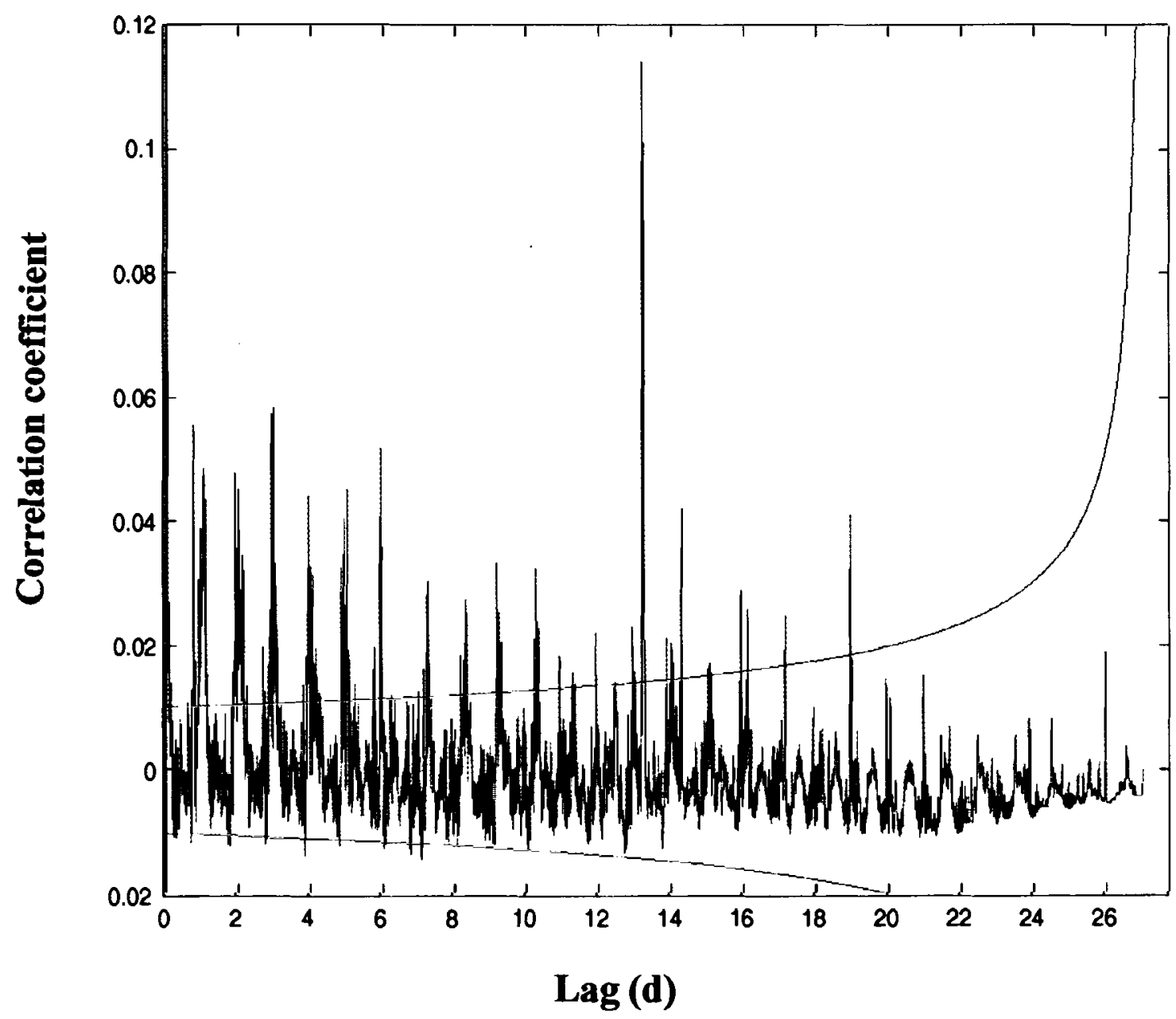

Figure 19. Autocorrelogram of total biovolume (2-5 $\mathrm{m}$ above TAPS) shows that biovolume is autocorrelated at lags of $1,2,3 \ldots \mathrm{d}(24,48,72 \ldots \mathrm{h})$. Zero lag has a correlation coefficient of one although the ordinate has been truncated to better show the pattern. Red lines represent confidence limits. There is a peak correlation coefficient at $13 \mathrm{~d}$ lag, likely an indication of the spring-neap cycle. 
Autocorrelogram of Bottom Current Speed on the Scale of Hours

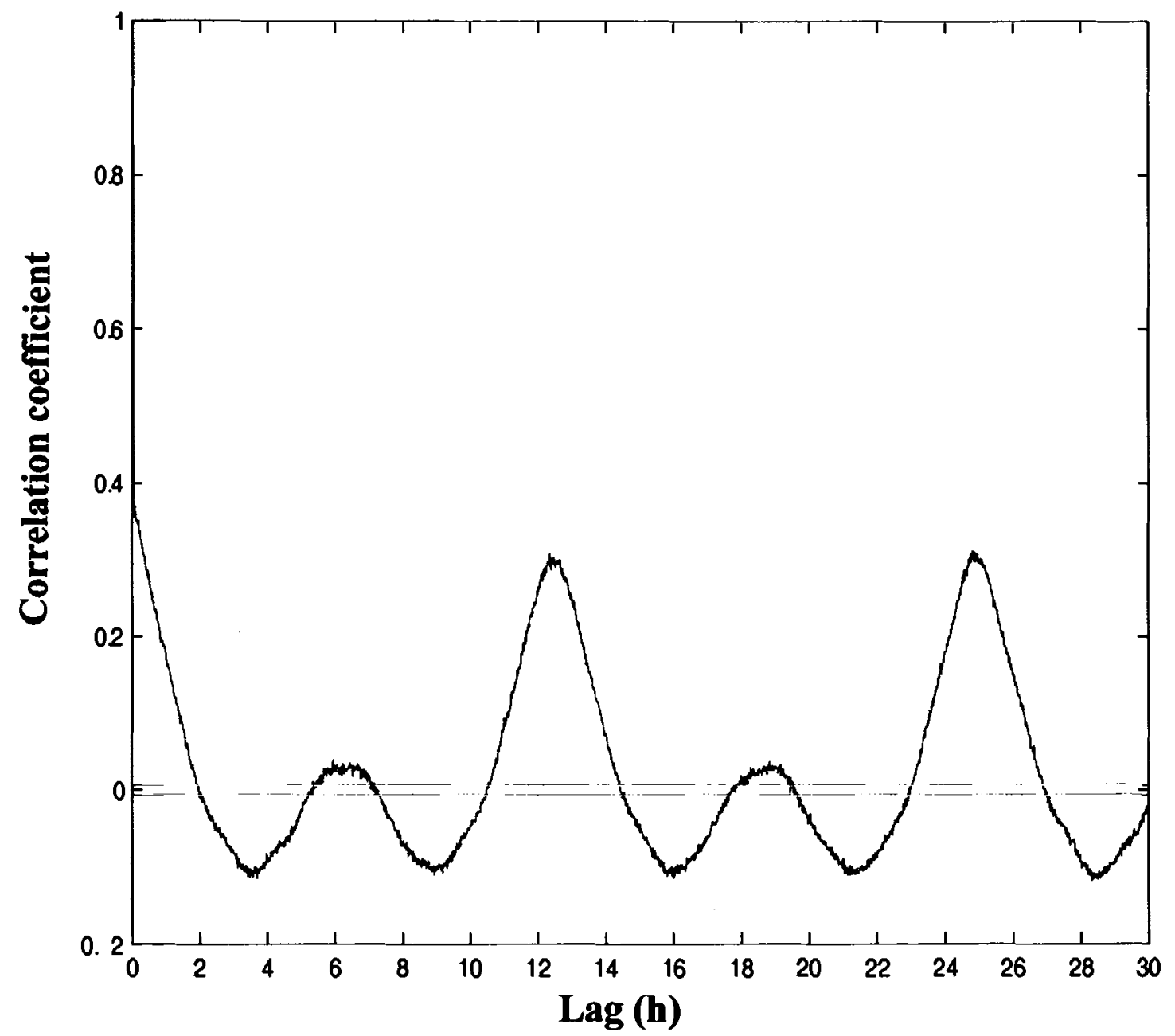

Figure 20. This autocorrelogram of bottom tidal current speed $0.1 \mathrm{~m}$ above the bottom near TAPS represents a system in which there are different bottom tidal speeds during incoming and outgoing tides. As expected, the autocorrelogram of bottom tidal speed shows strong autocorrelation at the M2 tidal period, a little over 12 and $24 \mathrm{~h}$. Zero lag has a correlation coefficient of one. Red lines represent $95 \%$ confidence limits. At 6 and $18 \mathrm{~h} \mathrm{lag}$ (e.g. the lag between a peak incoming tide and peak outgoing tide) there are slightly significant correlation coefficients. At lags of around 3.5, 9.5, 16, and 22 there are peaks of negatiave correlation. 
between a peak incoming tide and peak outgoing tide) there are slightly significant correlation coefficients, reflecting the asymmetry of the the two tides during one day. At lags of around $3.5,9.5,16$, and $22 \mathrm{~h}$ there are peaks of negative autocorrelation.

On a larger time scale, because the tidal speed time series is only $17 \mathrm{~d}$ long, it is not possible to resolve the influence of spring and neap tides.

The cross-correlogram of biovolume and bottom tidal speed (Figure 21) shows significant cross-correlation coefficients at lags of between approximately $0-3,11-15,23-$ $25 \mathrm{~h}$. These lags suggest that these two variables co-vary on a combination of a tidal and diurnal cycle. Wheras the onset of emergence corresponds with the beginning of tidal deceleration, peak abundances occur substantially later. On a larger time scale (Figure 22), the pattern of two daily peaks of positive cross-correlation persists on the order of days.

\section{Transmissometer results}

Frequently, the $265 \mathrm{kHz}$ channel of TAPS showed a repeating pattern of backscatter at a fixed period of the tide regardless of whether it was day or night (Figure 23). Although resuspended material is likely too small to be resolved using this frequency, this pattern could be the result of material moved off the bottom into the water column by tidal currents. If the backscatter measured by TAPS was due to resuspended material, a transmissometer, which measures attenuation, should have shown a similar pattern.

The transmissometer measured attenuation every $10 \mathrm{~min}$ for $5 \mathrm{~d}$ (Figure 24). The attenuation coefficient is higher during the daytime and decreases at night. Time series analysis shows a peak of positive autocorrelation at $24 \mathrm{~h}$ and peaks of negative 
Cross-correlogram of Total Biovolume and Bottom Tidal Speed on the Scale of Hours

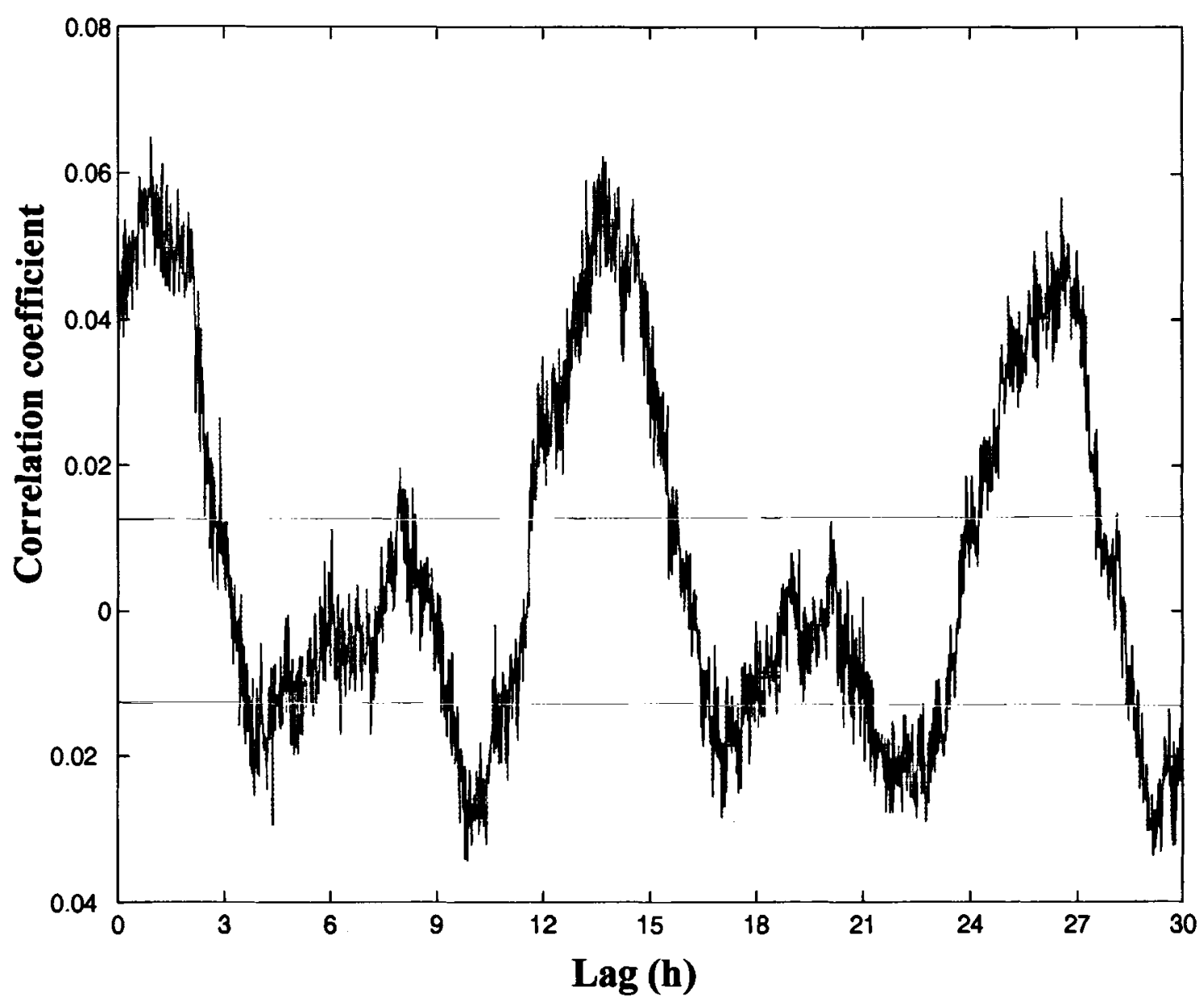

Figure 21. The cross-correlogram of biovolume and bottom tidal speed shows significant cross-correlation coefficients at lags of between approximately $0-3,11-15$ and 24-28 h. When the pattern of total biovolume lags behind the pattern of tidal speed by those increments, the patterns correlate more closely than when the tidal speed leads total biovolume by other increments. 


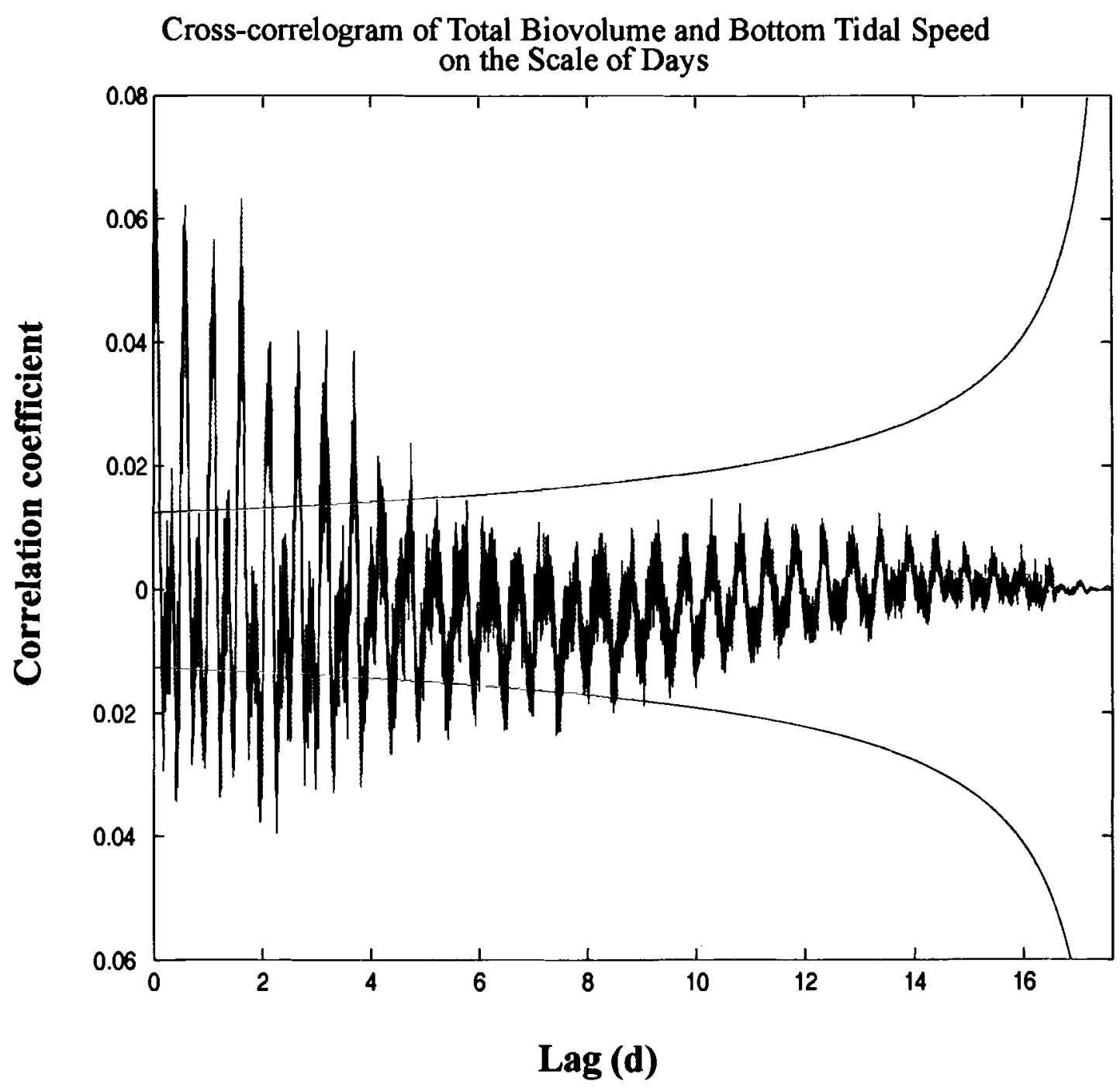

Figure 22. The pattern of two daily peaks of positive cross-correlation persists on the order of days. 


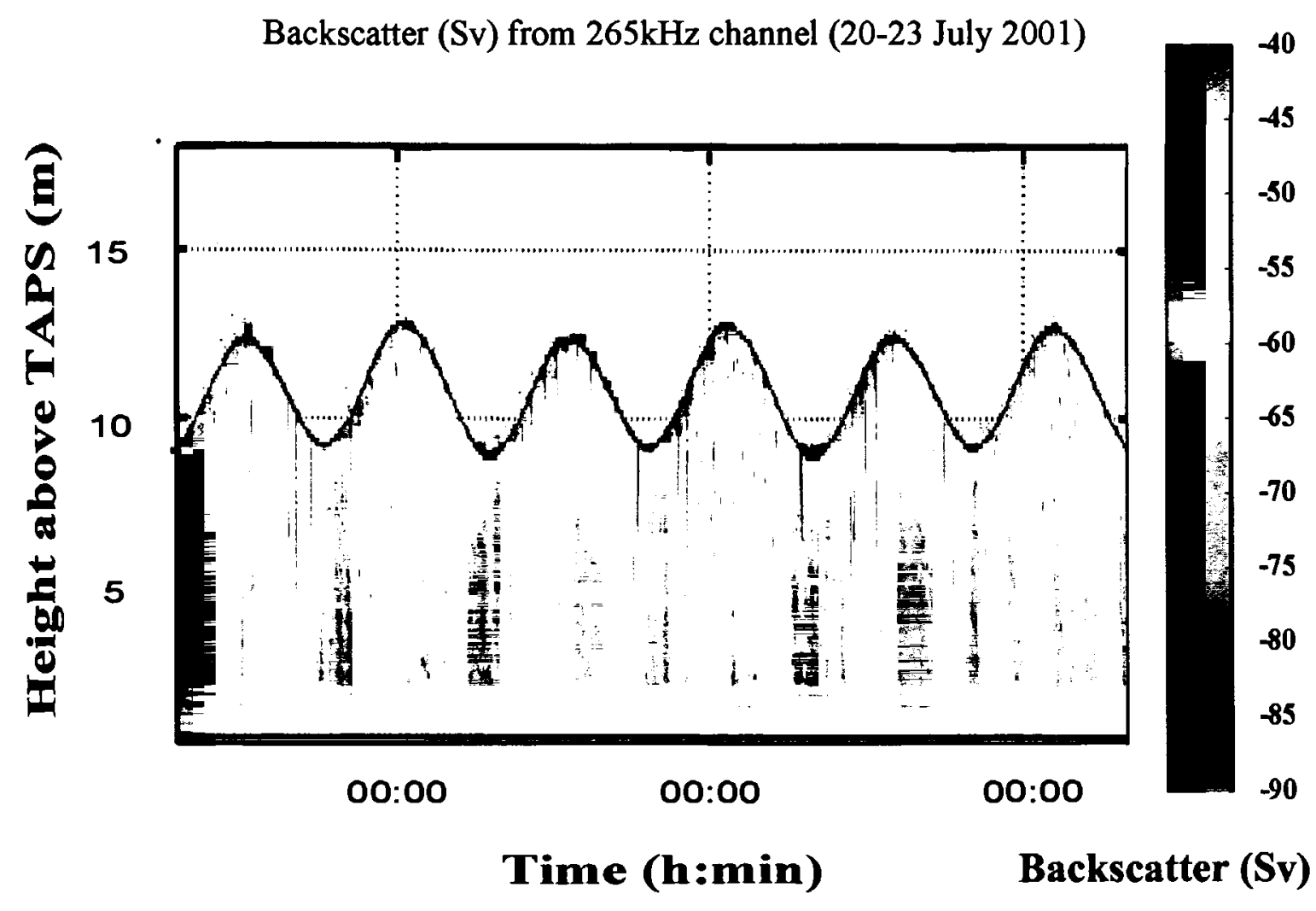

Figure 23. There is a repeating pattern of backscatter at a fixed period of the tide regardless of whether it is day or night. Resuspended material should be too small to be visualized with this channel. 
Attenuation Coefficient (c) : 18-25 November 2002

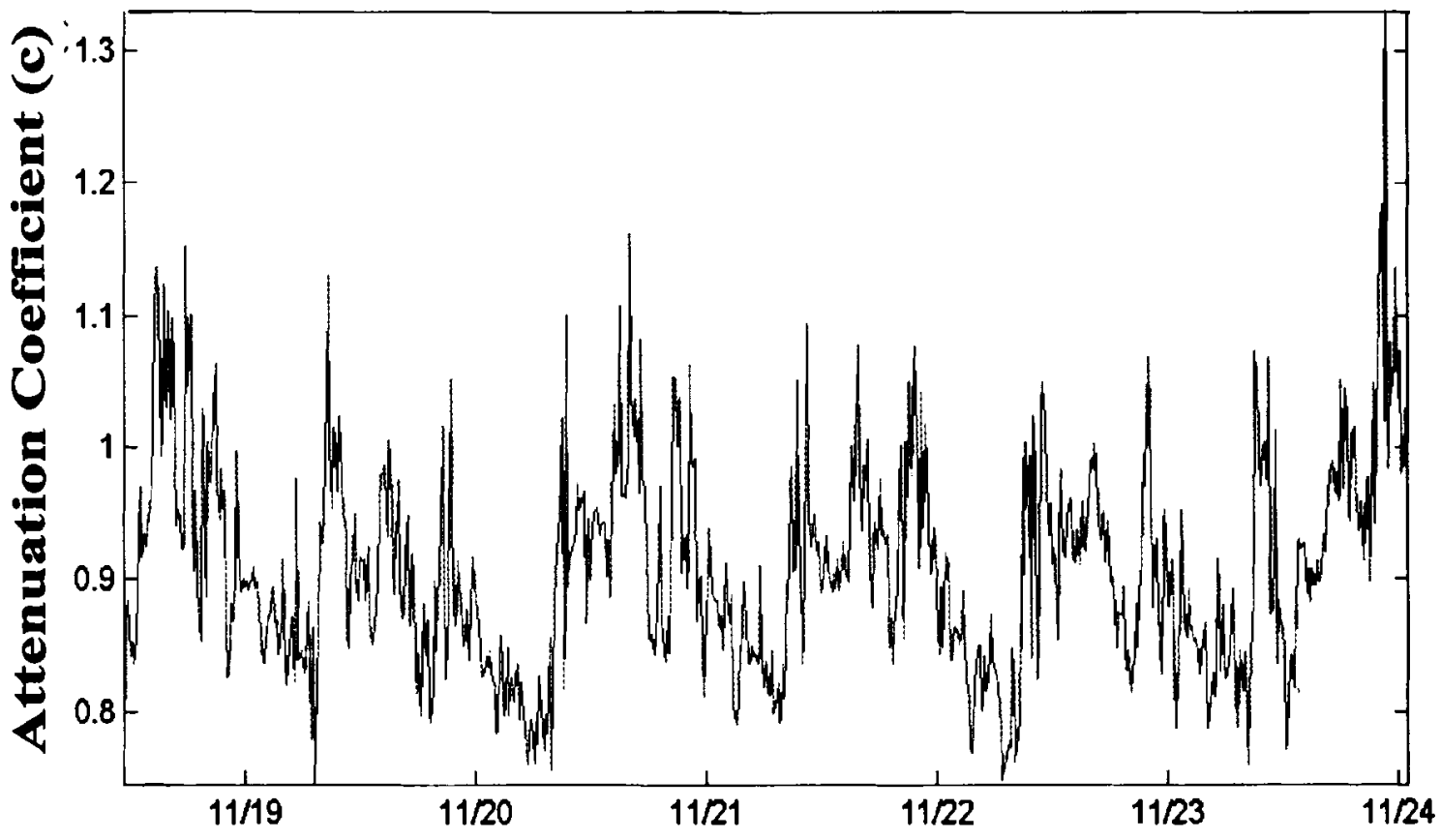

\section{Date}

Figure 24. The attenuation coefficient has a peak during the day and a trough at night. The dates on the $\mathrm{x}$-axis are positioned at 00:00 at the start of each labeled date. 
autocorrelation at 9 and $15 \mathrm{~h}$ (Figure 25). On a longer time scale, the daily pattern described above is persistent on the order of days (Figure 26). If resuspension is a major issue at our study site, one would expect the attenuation coefficient to be tidally modulated. Yet a peak of autocorrelation at 24 hours suggests that the pattern dominated by a diurnal signal. A time series using ADCP data from this time period is forthcoming. During the late fall, there is a disparity between the daytime and nighttime tides which could cause a tidal signal to appear as a diurnal signal. However, if the pattern of changes in the attenuation coefficient truly is diurnal it is probably a result of some biological process. Something must make the water clearer (to produce a lower attenuation coefficient) at night.

\section{Trap samples}

To test the hypothesis that Neomysis americana and Crangon septemspinosa participate in multiple emergence events nightly in the Damariscotta River estuary, emergence traps were deployed during the nights of $19-21$ August 2002. The biovolume plots for these dates (Figure 27) show multiple emergence events each night. Traps captured animals in both the first part of the night (until 0000 hours) and the second part of the night (until 0800 hours). Not all animals emerged at sunset.

The high-density emergence event calculated by my algorithm occurred in the second part of the night. If mysids were the only component of our signal, then one would expect that since the acoustic measurement of biovolume were greater during the second part of the night, the number of mysids captured would also be greater. However, there were fewer Neomysis americana captured in the second part of the night (mean = 


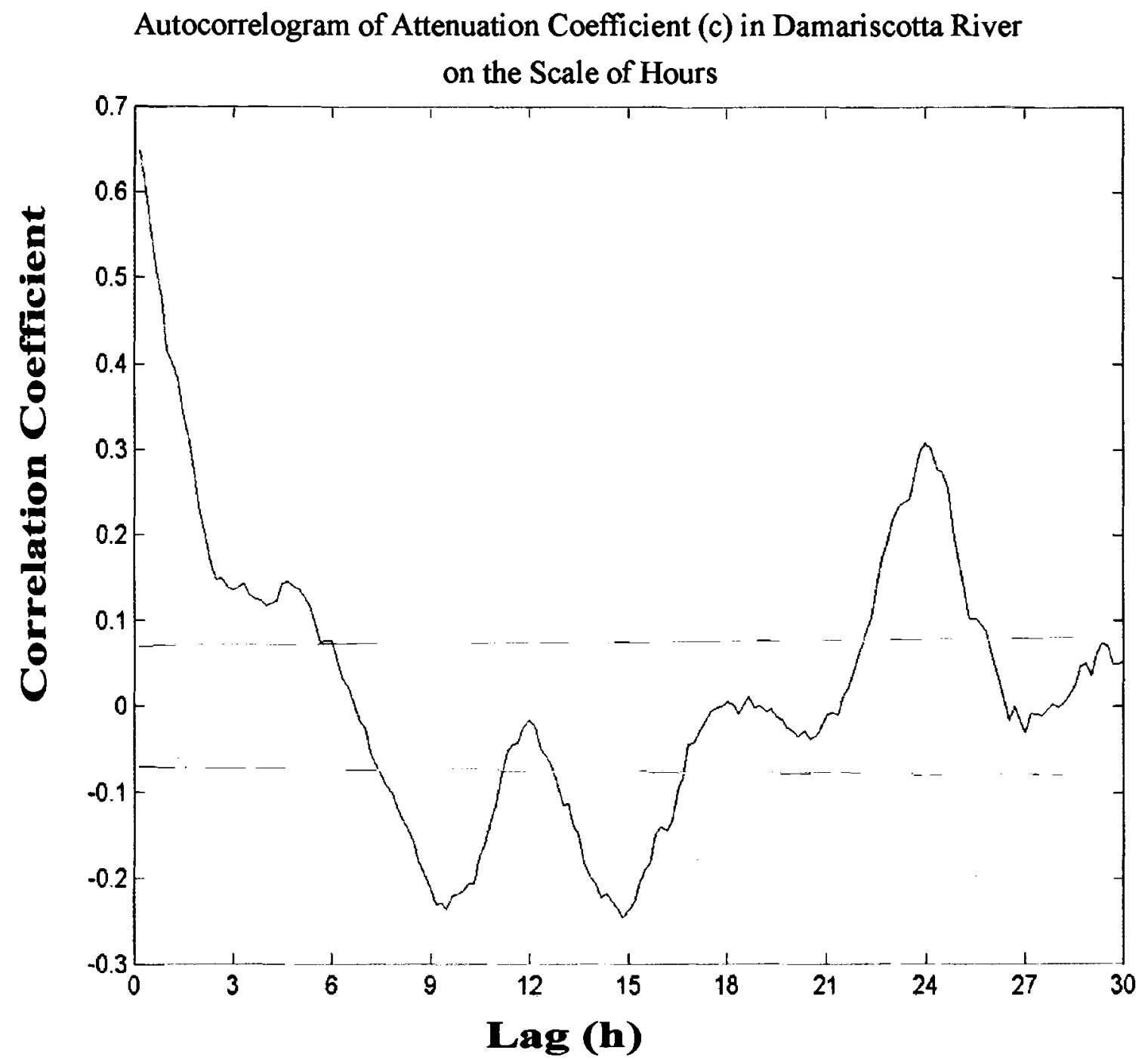

Figure 25. Autocorrelogram of the attenuation coefficient in the Damariscotta River near TAPS shows there is a peak of positive autocorrelation at $24 \mathrm{~h}$ lag. Zero lag has a correlation coefficient of one. The red lines represent confidence limits. There are two peaks of negative autocorrelation at 9 and $15 \mathrm{~h}$. 
Autocorrelogram of Attenuation Coefficient (c) in the Damariscotta River

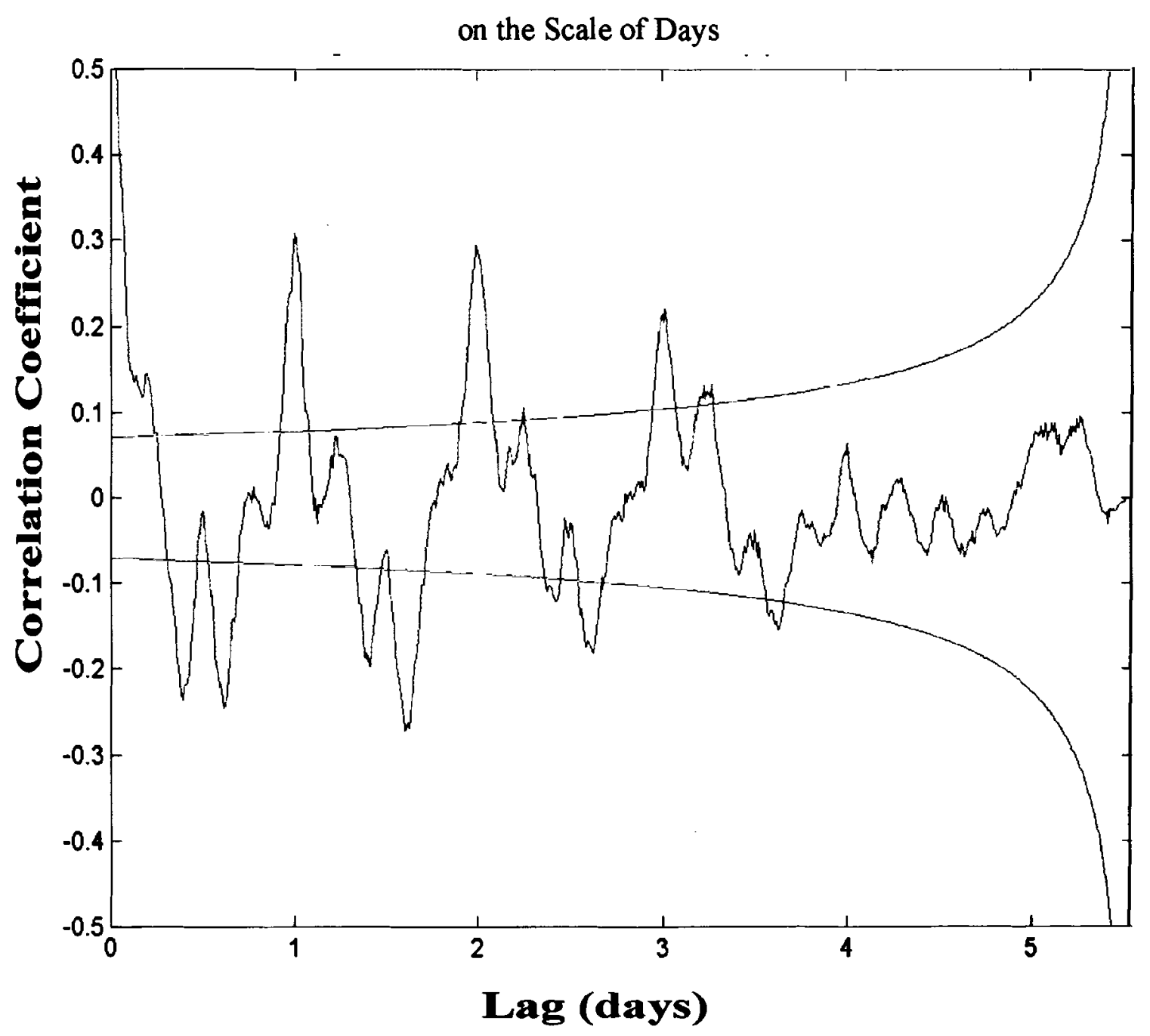

Figure 26. Autocorrelogram of the attenuation coefficient in the Damariscotta River near TAPS shows there is a repeating daily pattern. The red lines represent confidence limits. 
Total Biovolume (19-21 August 2002)
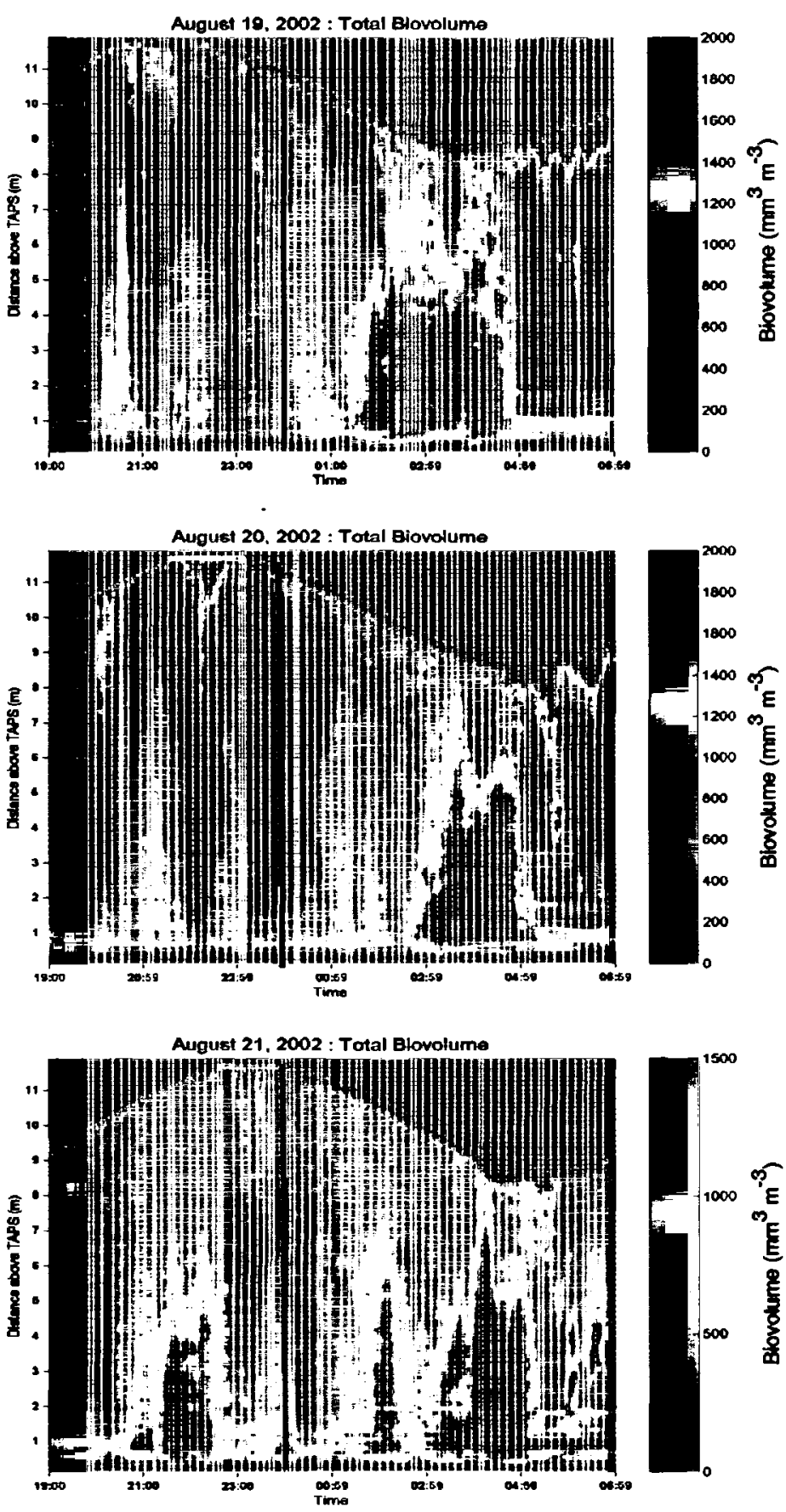

Figure 27: Multiple emergence events are visible in the total biovolume for the nights of 19-21 August 2002. Emergence-trap samples were collected at 00:00 (black line) and 08:00 to see if there was a difference between the number of organisms and species composition emerging during the two parts of the night. 
$55 \mathrm{~m}^{-2}$ ) than in the first part of the night (mean $=188 \mathrm{~m}^{-2}$ ) (Figure 28). Although the difference was not significant $(P=0.09)$, it was suggestive.

Since the ratio of mysids captured in different parts of the night did not match expectations based on backscatter measurements, it is possible that there are multiple constituents creating the acoustic pattern. Another possibility is that the high-density event in the second part of the night that was detected using acoustic methods is created by mysids, but that the mysids are not captured in emergence traps at that time because they are not emerging. It is possible that the event detected by the algorithm is a "congregation" event and not an "emergence event." Lastly, the algorithm to define emergence uses both intensity and duration as criteria. As a result, it is possible that the sunset event which the algorithm does not select due to its short duration is of a greater intensity (with more animals emerging) than the later event which the algorithm does select.

There was no difference between the number of large Crangon septemspinosa ( $>$ $1 \mathrm{~cm})$ captured in the first part and the second part of the night $(P=0.768)$. Nor was there a difference between the number of small Crangon septemspinosa $(<1 \mathrm{~cm})$ captured in the two parts of the night $(P=0.407)$. There were too few organisms of any species besides Neomysis americana and Crangon septemspinosa to perform a comparison between the two parts of the night. The date of trap deployment had no effect on the number of total mysids or Crangon captured. This suggests that total emergence abundance might be similar over periods of a few days.

The population composition of Neomysis americana by sex and developmental stage differed between the two parts of the night. Neomysis americana were classified 
Number of Neomysis americana Captured in the First versus the Second Part of the Night

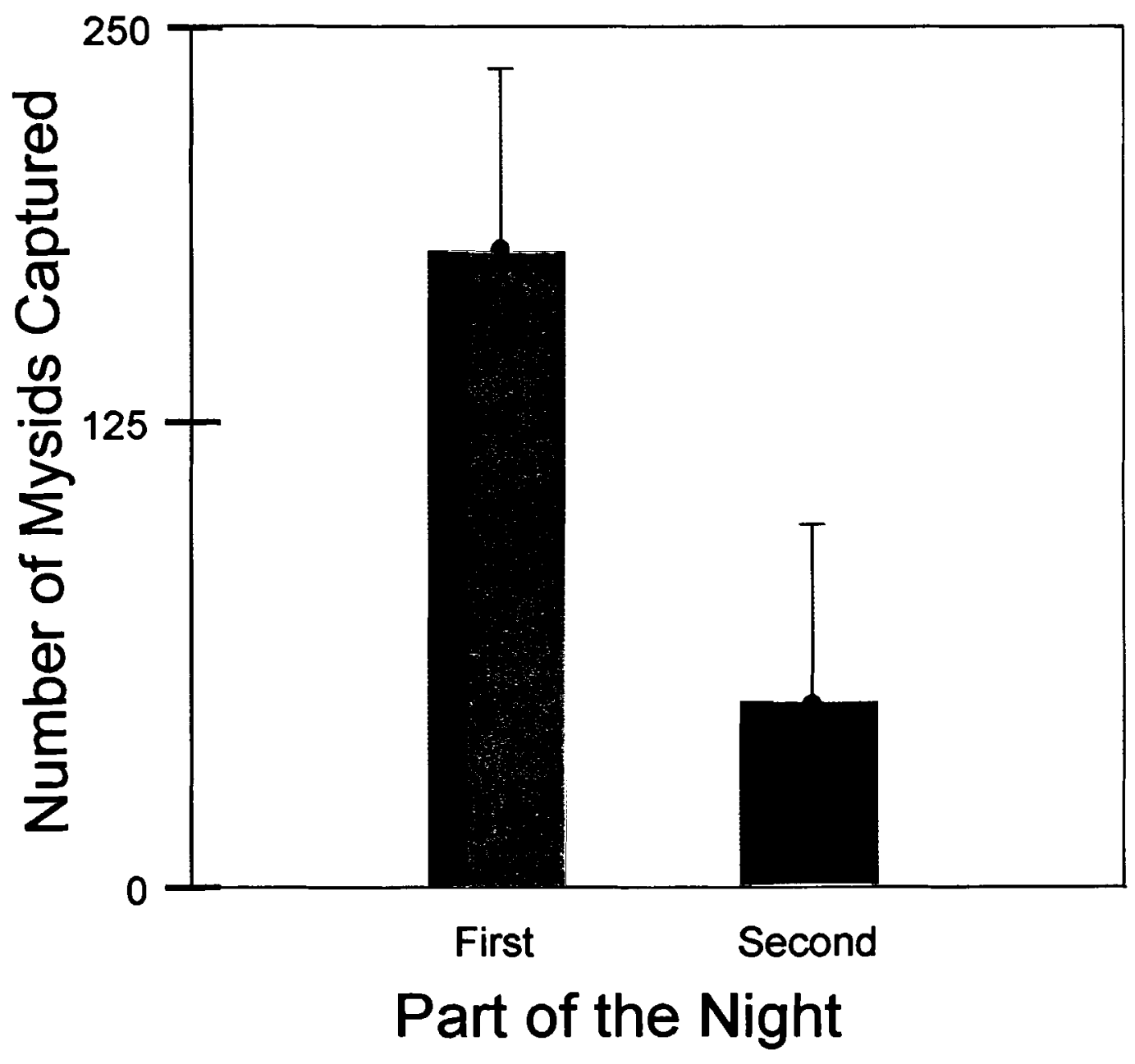

Figure 28: More mysids were captured in the first part of the night (mean $=187$, standard deviation $=245$ ) than in the second part of the night (mean $=55$, standard deviation $=69$ ). 
into the following categories based on morphology: stage 1 females, stage 2 females, stage 3 females, females with a brood pouch but no eggs, juveniles, and males (see Mauchline 1980). There were more juveniles and females with an empty brood pouch captured in the first part of the night than in the second $(P=0.052$ and 0.019 , respectively). As there were more total mysids captured in the first part of the night, these differences may not be significant.

I therefore analyzed the sex and developmental categories difference as percentages of the total Neomysis americana captured in each trap. Although there was neither a significant difference between the percent of each trap composed of males nor the percent composed of juveniles between the two parts of the night, females composed a significantly $(P=0.01)$ larger percentage of each trap catch in the first part of the night $($ mean $=29.3 \%)$ than in the second part of the night $($ mean $=18.4 \%)$. There was a greater percentage of stage-one females and stage-three females captured per trap in the first part of the night $(P=0.051$ and $P=0.004$ respectively). The mean percentage of each trap comprising stage-two females and females with a brood pouch and no eggs was higher in the first than in the second part of the night. However the sample sizes were too small to draw any strong conclusions $(P=0.70$ and $P=0.16$, respectively).

During the nights sampled, the slack tides considered here were during the first part of the night. The slack tide in the second part of the night was near daybreak. It is possible that females preferentially emerge around times of decelerating tidal speeds when it is dark. The first part of the nights sampled here contained both an incoming and an outgoing tide, whereas the second part was dominated by outgoing tides. Therefore, another hypothesis is that female mysids preferentially emerge during incoming tides. 
The short duration and low temporal resolution of this trap study make the results inconclusive. However, the different emergence patterns of different developmental stages of mysids merit further investigation.

The percentage of mysids in each trap that was male and the percentage that was female stage three varied with date of deployment $(P=0.004$ and $P=0.001$, respectively). Males composed a greater percentage of emerging mysids on the night of 19 August 2002 (mean $=40.5 \%$ ) than on the other two nights (means $=19.9 \%$ and 22.6\%). The percentage of mysids in each trap that were stage-three females changed among the three nights. However, they always composed $<10 \%$ of the mysids in each trap. The small sample size again weakens any conclusion.

\section{Responsibility for the high-density emergence event: possible scenarios}

One of the problems with acoustic analysis is that backscatter patterns cannot yet be assigned to taxa (although that is an ultimate goal of acousticians). It is certain neither what particles are responsible for the backscatter patterns described in this paper nor what organisms might be responsible for the emergence events. Emergence trapping suggests that mysids and Crangon are responsible for the nocturnal emergence, but those animals have never been caught during the day. It is possible that mysids are responsible for both the diurnal and the nocturnal emergence. Mysids might emerge during the day but not enter emergence traps when there is light. Although such trap avoidance selectively in daylight has never been documented, mysids are notoriously good at evading plankton nets (e.g. Clutter and Anraku 1968).

A more likely scenario is that at least two participants create the pattern. One constituent emerges at a certain time of tide, day and night. Only at night does the 
second constituent emerge in concert with the first. During the day the second constituent remains on or in the benthos. The first constituent may be smaller or less abundant than the other constituent due to the smaller magnitude of emergence during the day. However, the greater magnitude of nocturnal emergence could be the result of the combined biovolume of two constituents. Further analysis using size-class information could help sort out the components of the pattern. An interesting approach would be to subtract the daytime emergence backscatter signal from the nighttime signal. It is possible that such a removal would result in a strictly nocturnal pattern, like that more traditionally chronicled for mysids. The second high-density emergence discussed in this paper may be the additive result of two patterns in phase with one another.

From emergence trapping, it is likely that the "second constituent" discussed above comprises Neomysis americana and Crangon septemspinosa. However, it is unclear what organism or particle is the "first constituent" that emerges during both the day and the night. The source of the pattern could be non-living. Emergence events happen at times of decreasing current velocity during both the day and the night. It is possible that the increased turbulence associated with high flow velocities results in resuspension of particles from the benthos. Resuspension could be responsible for part of the backscatter signal. However, at our lowest frequency $(265 \mathrm{kHz})$, the wavelength is too long to be heavily influenced by particles the size of sand or silt. Yet the daytime emergence is visible on some days even in the backscatter measurements of that channel. Also, transmissometer measurements have shown that patterns of attenuation do not seem to match patterns of backscatter change as one might expect if resuspended aggregates account for the backscatter. 
Another hypothesis is that the "first constituent" is an animal population reacting to the physical properties associated with decelerating tidal currents. Possibly a population is using the resuspension or turbulence associated with deceleration as camouflage to enter the water column to feed or to molt. Alternately, animals could select a time of moderate and decelerating tidal velocities to enter the water column to avoid strongest tidal velocities that might result of large displacement. If the tide is decelerating when the animal emerges and if the animal descends before the tide speeds up again, the first moment of emergence would have the strongest tidal velocity that an animal will encounter.

Decelerating tidal currents indicate the approach of slack tide and tidal direction change. Depending upon the duration of emergence, an animal could spend some time in the water column traveling one direction along the estuary, followed by some time traveling the other direction. In this way, an animal could avoid large excursions.

\section{CONCLUSION}

This study demonstrates that emergence can be consistently identified in an environment with high tidal velocities. Our acoustic results suggest that emergence in the Damariscotta River Estuary is tidally modulated. In the Damariscotta River, high-density emergence events at night and during the day start at a fixed phase of the tide (during deceleratioin, approximate $3 \mathrm{~h} 30 \mathrm{~min}$ after slack). Our results also suggest that emergence in an environment with strong tidal velocities may be more temporally complex than previous studies by non-acoustic means have been able to resolve. 


\section{REFERENCES}

Alldredge, A. L. and J. M. King. 1980. Effects of moonlight on the vertical migration patterns of demersal zooplankton. J. Exp. Mar. Biol. Ecol. 44: 133-156.

Chatfield, C. 1975. The analysis of time series: theory and practice. Chapman and Hall.

Clutter, R.I. and M. Anraku. 1968. Avoidance of samplers. In, Zooplankton Sampling, Monographs on oceanographic methodology, 2. UNESCO, Paris. 57-76.

De Vries, M. C., R. A. Tankersley, R. B. Forward, Jr., W. W. Kirby-Smith and R. A. Luettich, Jr. 1994. Abundance of estuarine crab larvae is associated with tidal hydrologic variables. Mar. Biol. 118: 403-413.

Fortier, L. and W. C. Leggett. 1983. Vertical migration and transport of larval fish in a partially mixed estuary. Can. J. Fish. Aquat. Sci. 40: 1543-1555.

Greenlaw, C. F. and R. K. Johnson. 1983. Multiple-frequency acoustical estimation. Biol. Oceanogr. 2: 227-252.

Hill, A. E. 1991 (a). A mechanism for horizontal zooplankton transport by vertical migration in tidal currents. Mar. Biol. 111: 485-492.

Hill, A. E. 1991 (b). Vertical migration in tidal currents. Mar. Ecol. Prog. Ser. 75: 39-54.

Holliday, D. V. 1993. Zooplankton acoustics, p. 733-740 In, B.N. Desai [ed.], Oceanography of the Indian Ocean. Balkema.

Holliday, D. V. 1997. Extracting bio-physical information from the acoustic signatures of marine organisms, p. 619-624 In, N. R. Anderson and B.J. Zahuranec [eds.], Ocean sound scattering and prediction. Plenum.

Hostens, K. and J. Mees. 1999. The mysid-feeding guild of demersal fishes in the brackish zone of the Westerschelde estuary. J. Fish Biol. 55(4) : 704-719.

Kaartvedt, S. 1986. Diel activity patterns in deep-living cumaceans and amphipods. Mar. Ecol. Prog. Ser. 30: 243-249.

Kringel, K., D. V. Holliday and P. A. Jumars. 2003. A shallow scattering layer : highresolution acoustic analysis of nocturnal vertical migration from the seabed. Limnol. Oceanogr. Accepted for publication.

Lalli, C. M. and T. R. Parsons. 1997. Biological oceanography an introduction. Butterworth-Heinemann. 
LaRow, E. J. 1970. The effect of oxygen tension on the vertical migration of Chaeborus larvae. Limnol. Oceanogr. 15 : 357-362.

Manderson, J. P., B. A. Phelan, A. J. Bejda, L. L. Stehlik and A. W. Stoner. 1999. Predation by striped searobin (Prionotus evolans, Triglidae) on young-of-theyear winter flounder (Pseudopleuronectes americanus, Walbaum): examining prey size selection and prey choice using field observations and laboratory experiments. J. Exp. Mar. Biol. and Ecol. 242: 211-231.

Mathworks. 1998. MATLAB : Signal Processing toolbox. Mathworks.

Mauchline, J. 1980. The biology of mysids and euphausids. Adv. Mar. Biol. 18: 1-680.

McGehee, D. E., R. L. O'Driscoll and L. V. Martin-Traykovski. 1998. Effects of orientation on acoustic scattering from Antarctic krill at $120 \mathrm{kHz}$. Deep-Sea Research II 45: 1273-1294.

Medwin, H. and C. S. Clay. 1998. Fundamentals of acoustical oceanography. Academic Press.

Moore, J. W. and I. A. Moore. 1976. The basis of food selection in flounders, Platichthys flesus (L.), in the Severn Estuary. J. Fish Biol. 9(2) : 139-156.

Oh, C. W., R. G. Hartnoll and R. D. M. Nash. 2001. Feeding ecology of the common shrimp Crangon crangon in Port Erin Bay, Isle of Man, Irish Sea. Mar. Ecol. Prog. Ser. 214: 211-223.

Oishi, K. and M. Saigusa. 1997. Nighttime emergence patterns of planktonic and benthic crustaceans in a shallow subtidal environment. J. of Oceanography 53: 611-621.

Olhorst, S. L. 1982. Diel migration patterns of demersal reef zooplankton. J. Exp. Mar. Biol. Ecol. 60: 1-15.

Pieper, R. E. and D. V. Holliday. 1984. Acoustic measurements of zooplankton distributions in the sea. J. Cons. Int. Explor. Mer 41: 226-238.

Rothlisberg, P. C., J. A. Church and A. M. G. Forbes. 1983. Modeling the advection of vertically migrating shrimp larvae. J. Mar. Res. 41: 511-538.

Takahashi, K. and K. Kawaguchi. 1997. Diel and tidal migrations of the sand-burrowing mysids Archaeomysis kokuboi, A. japonica and Tiella oshimai, in Otuschi Bay, northeastern Japan. Mar. Ecol. Prog. Ser. 148: 95-107. 
Trevorrow, M. V. and Tanaka, Y. 1997. Acoustic and in situ measurements of freshwater amphipods (Jesogammarus annadalei) in Lake Biwa, Japan. Limnol. Oceanogr. 42: $121-132$.

Wang, Z. and J. C. Dauvin. 1994. The suprabenthic crustacean fauna of the infralittoral fine sand community from the Bay of Seine (Eastern English Channel): composition, swimming activity and diurnal variation. Cah. Biol. Mar. 35: 135155.

Wet Labs. 2002. C-Star User's Guide Revision I. Wetlabs.

Wilcox, J. R. and P. Jeffries. 1974. Feeding habits of the sand shrimp Crangon septemspinosa. Biol. Bull. 146: 424-434.

Woolridge, T. and T. Erasmus. 1980. Utilization of Tidal Currents by Estuarine Zooplankton II: $107-114$. 


\section{APPENDIX : ORIGINAL MATLAB PROGRAMS}

\section{Centercorrectpercentile}

This program is a "gradient filter" to correct for the gradient in TAPS biovolume data. Backscatter observations from bins farther away from TAPS were greater than observations from bins close to TAPS. To correct for this, I rectify the data so that the lowest observations in each depth bin are the same. I assume that over a long enough time period each bin will be more or less "empty" of particles at some point. I further assume that a measurement of an "empty" bin far from TAPS and an "empty" bin near TAPS should yield the same amount of backscatter.

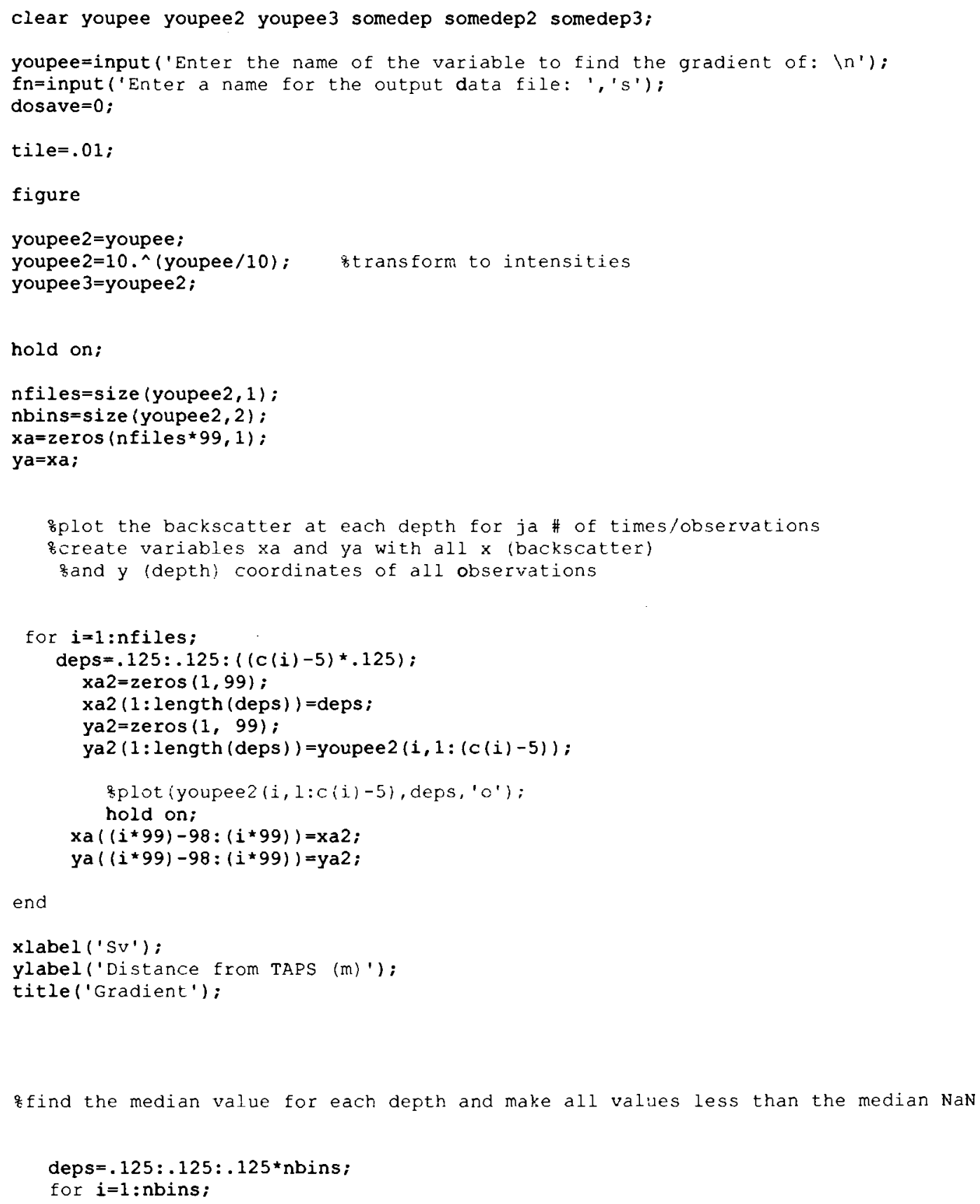




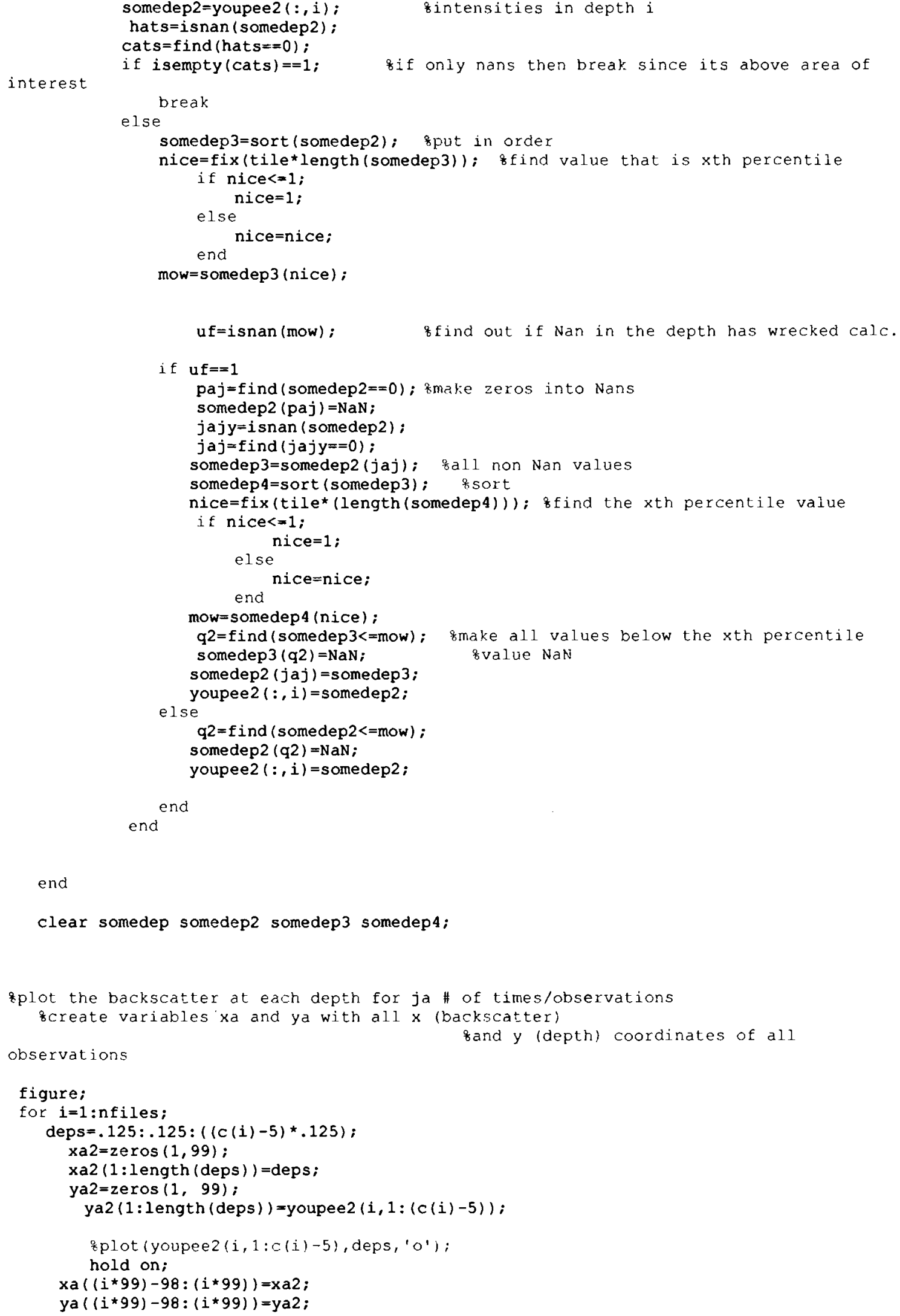




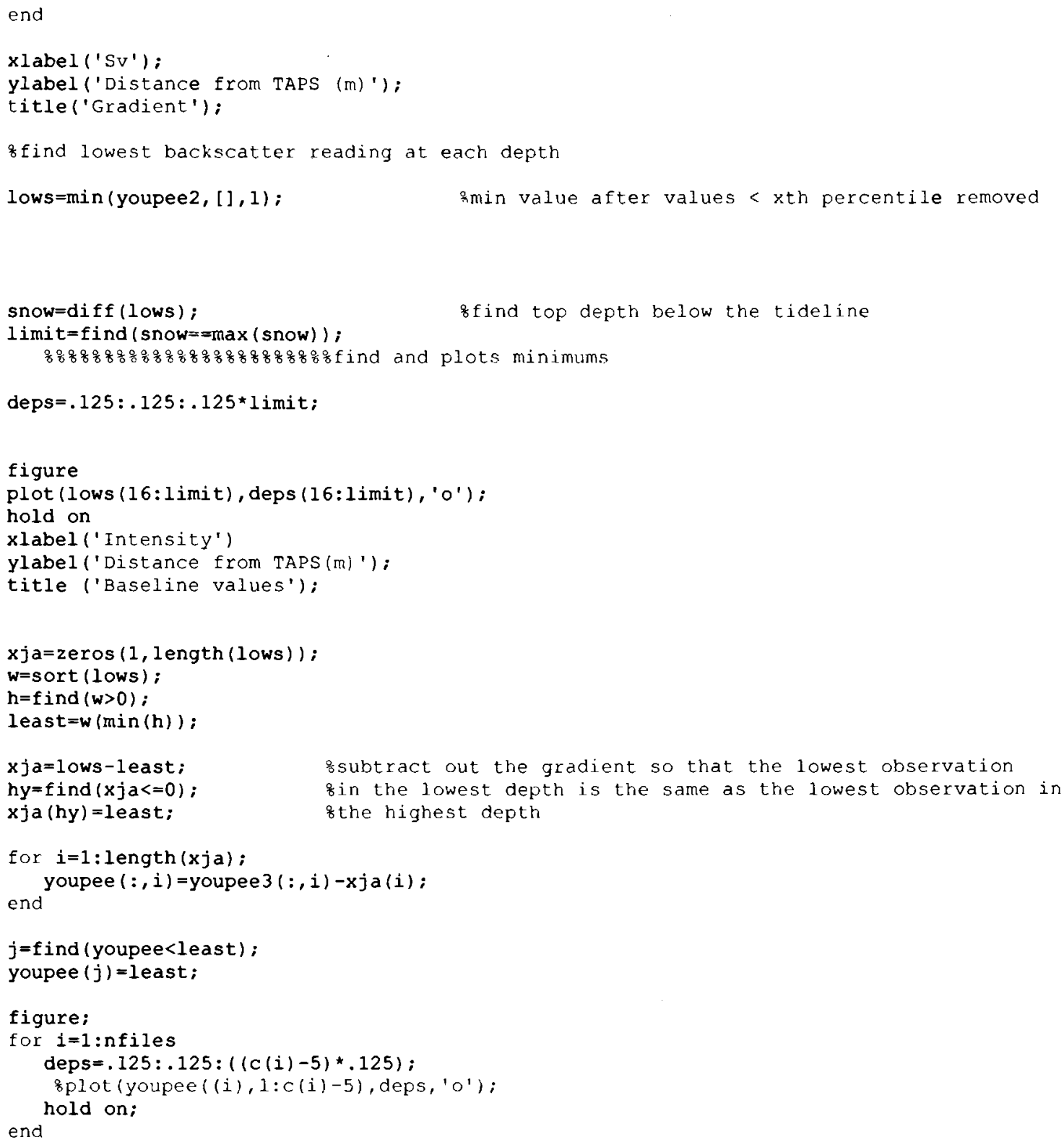


Timecorrecttester2

This program corrects the time stamp associated with each observation so that there are no identically labeled observations. It also interpolates between values if there is a gap longer than 60 seconds between observations.

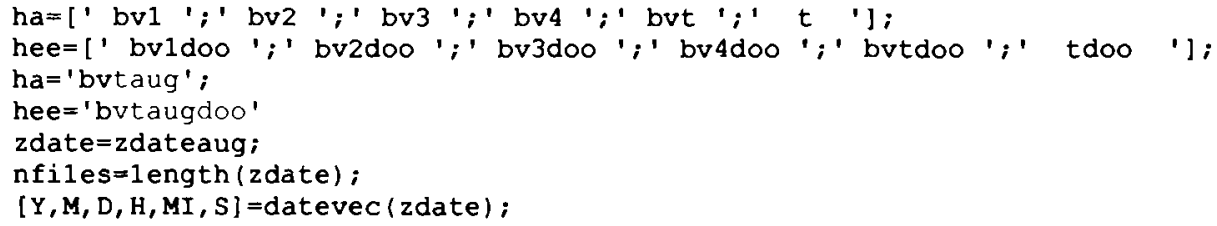




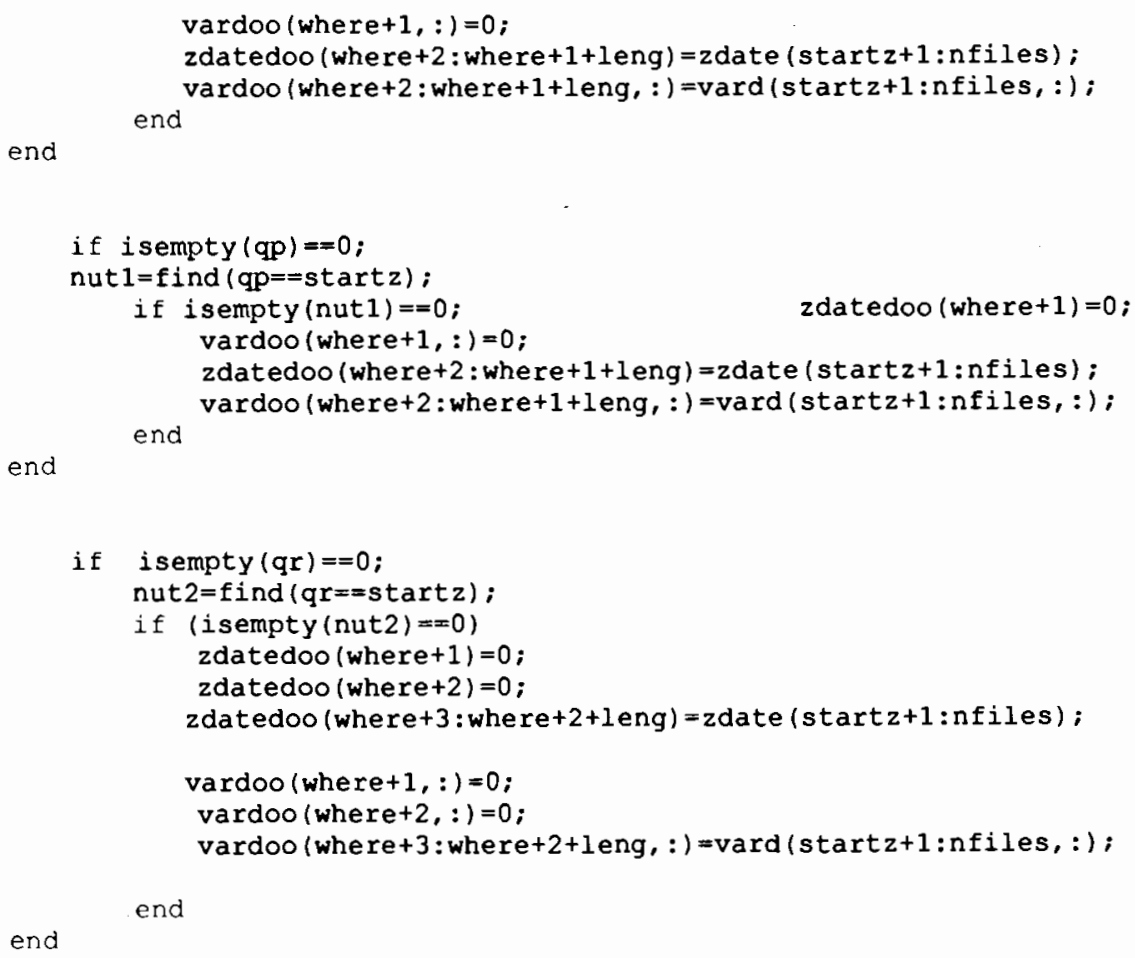




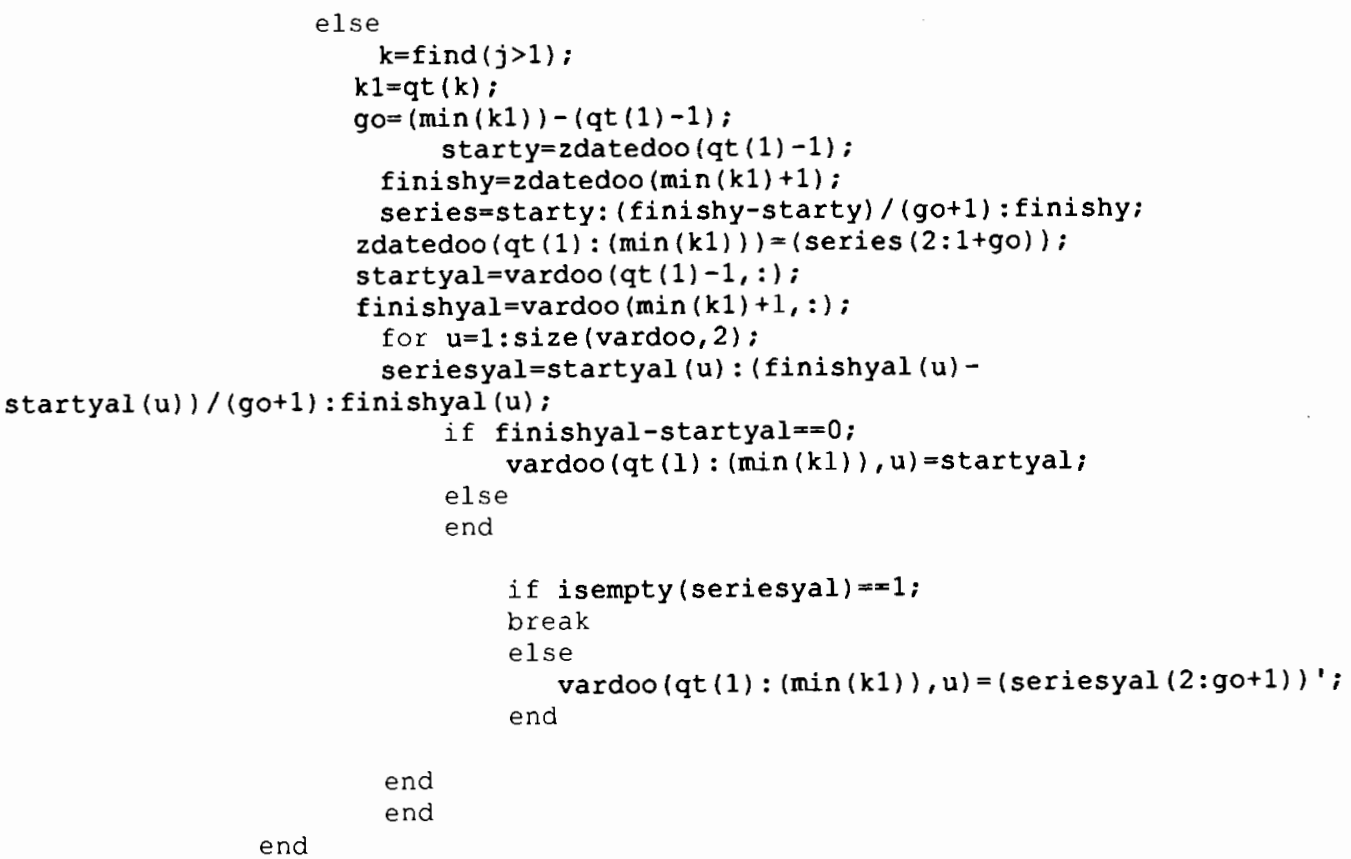




\section{Findbigstart}

The purpose of this program is to quantify the start time of an emergence event. The algorithm finds (for each depth) observations above a threshold value. The threshold value is selected by stepping through progressively large values until there are fewer than 240 observations (in twelve hours) above the threshold value. The observations above the threshold value are then searched to find the longest series of observations at each depth. A "start time" for the longest run of observations above a threshold value is selected for each depth. The mode of the "start times" provides one "start time" applicable to the whole water column.

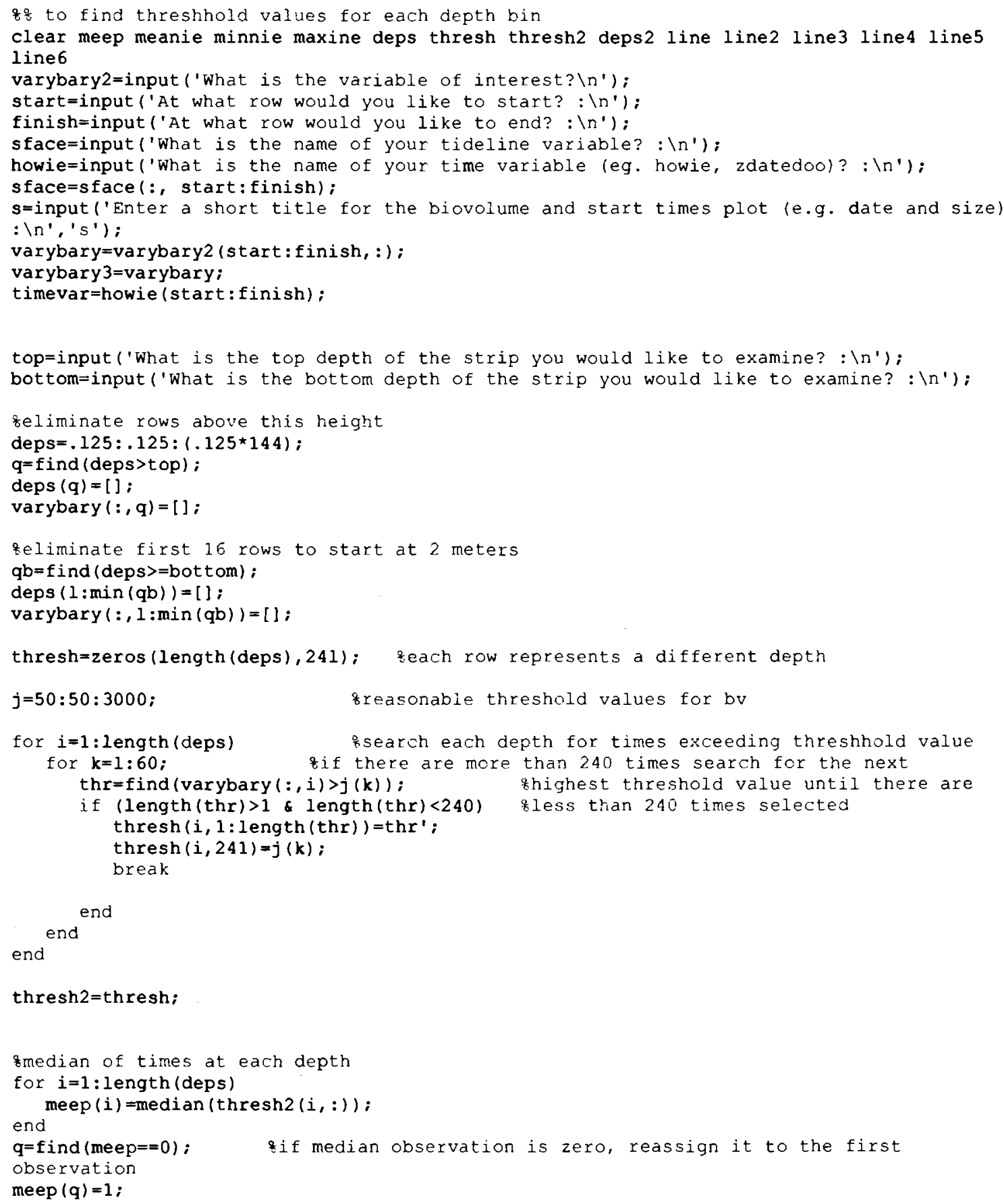




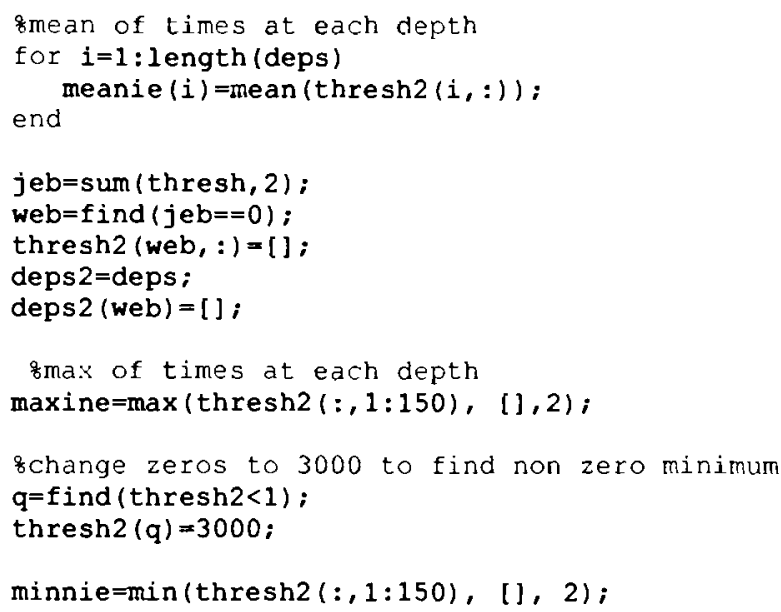




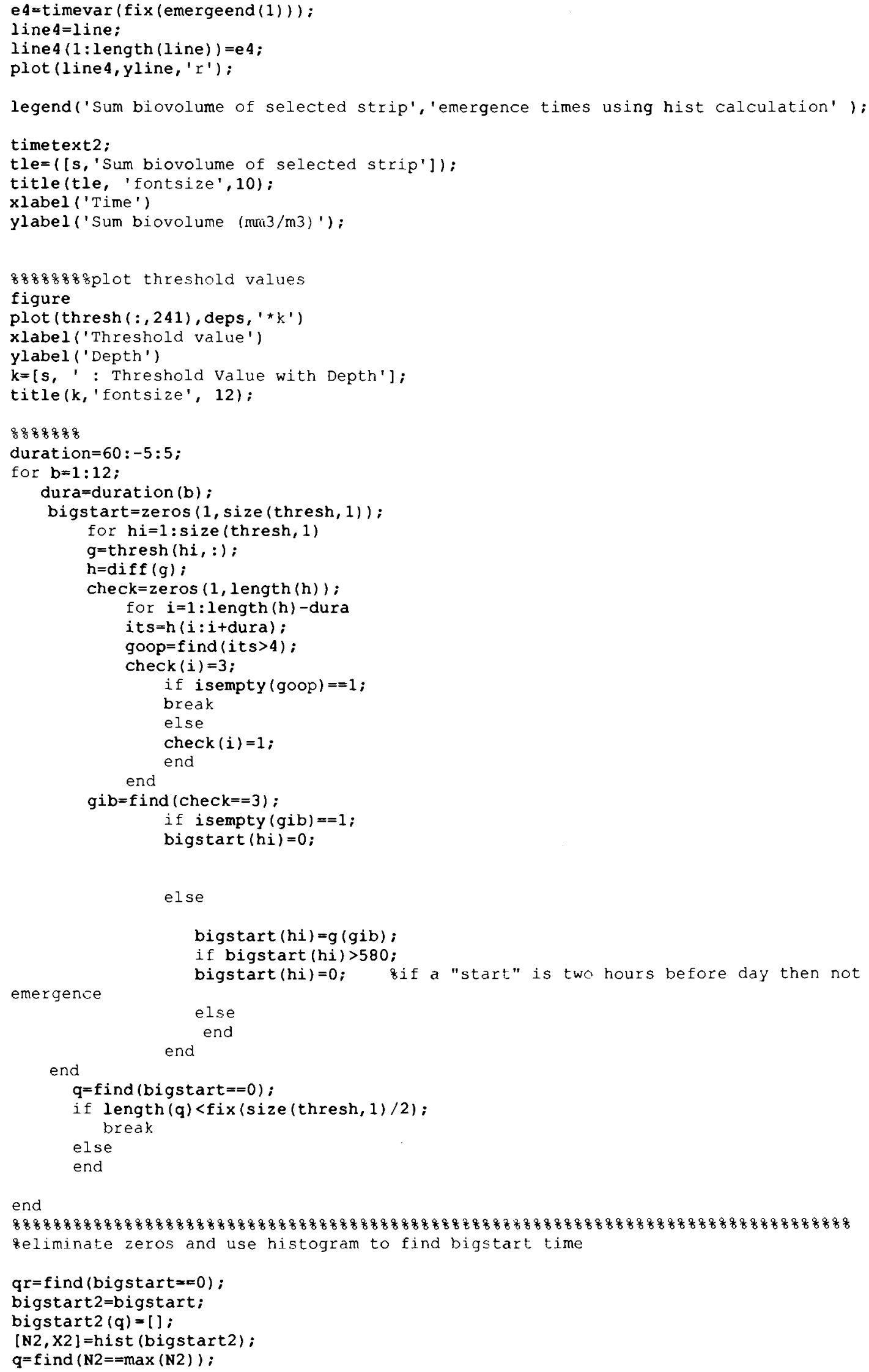




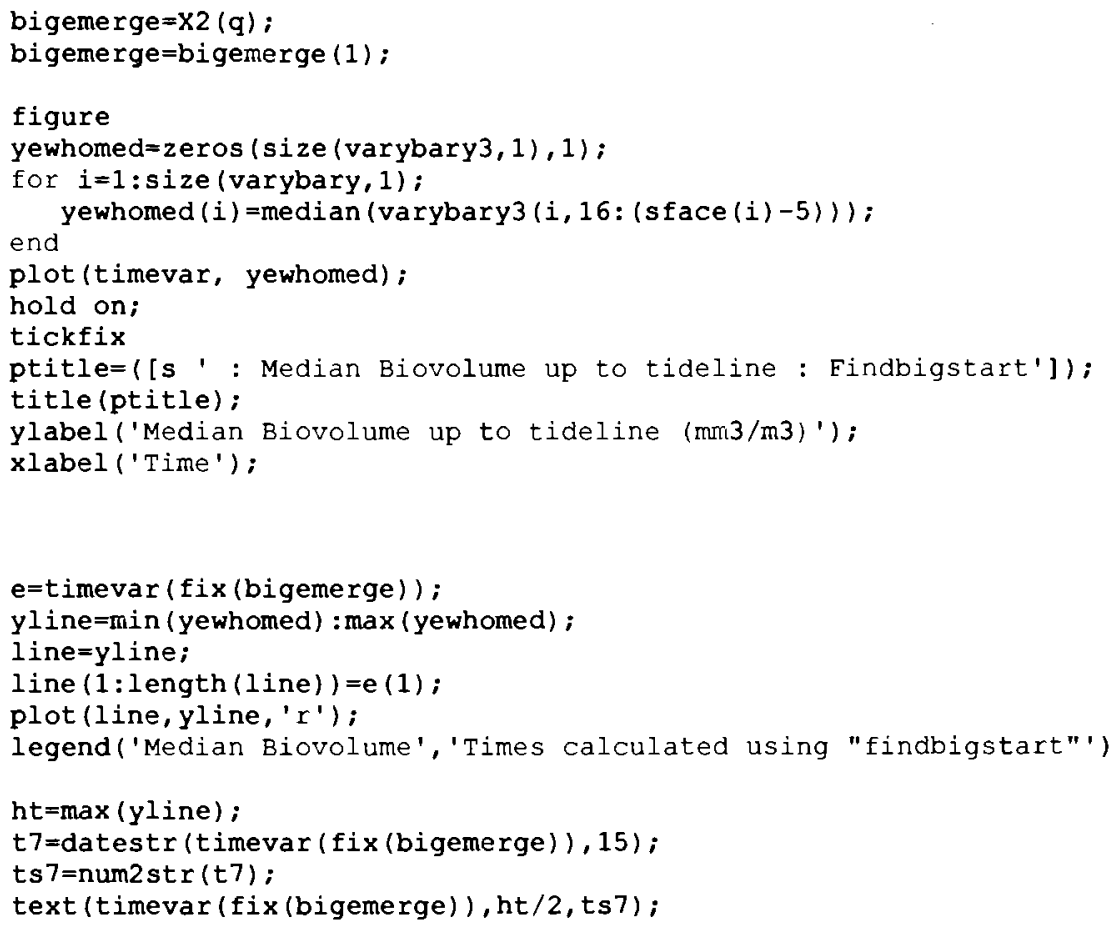




\section{Loadtransmiss}

This program is designed to load transmissometer data into Matlab from a text file.

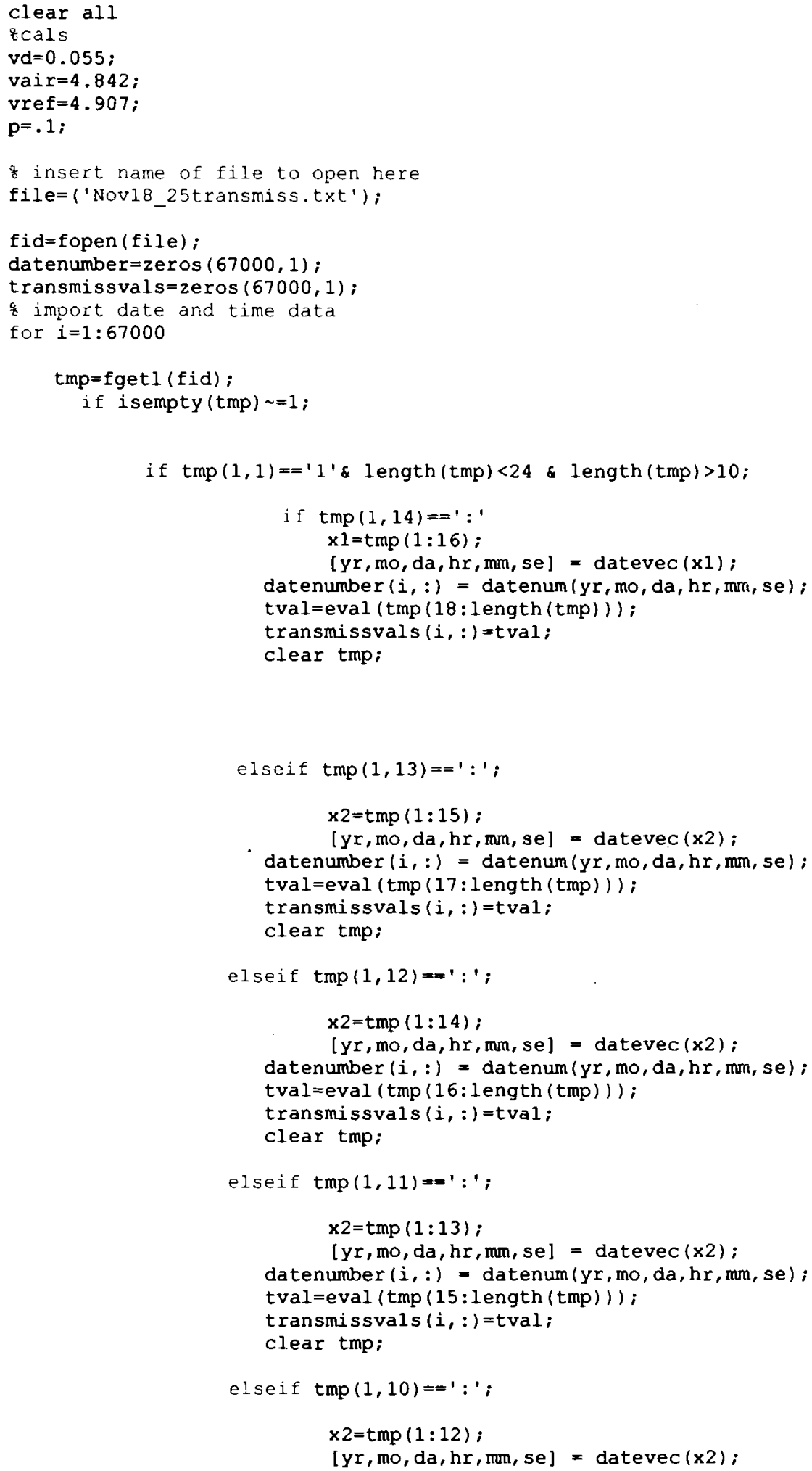




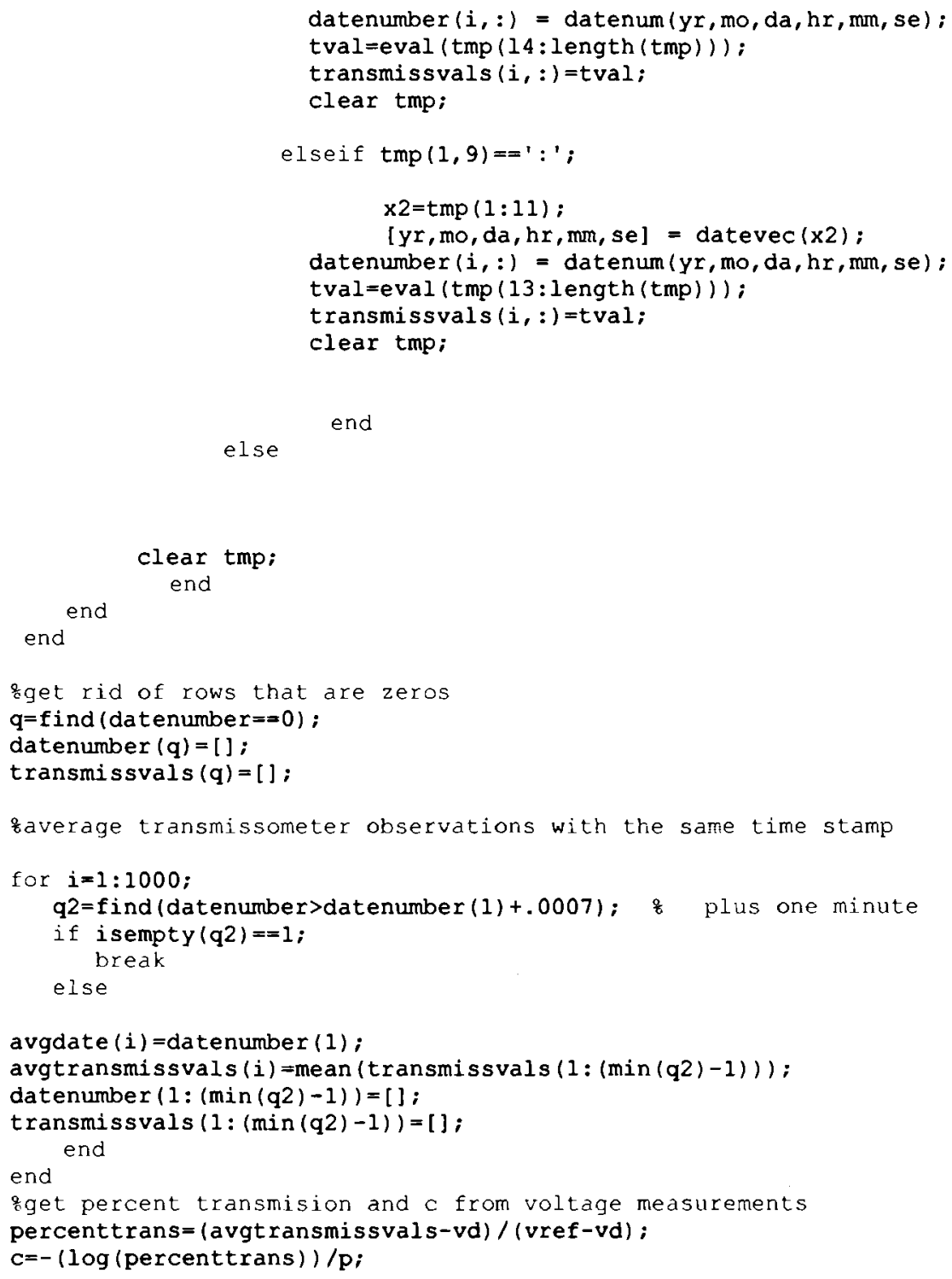




\section{BIOGRAPHY OF THE AUTHOR}

Leslie Taylor was born in Los Angeles, California. She graduated from Ursuline High School in Santa Rosa, California. In 1998, she received her undergraduate degree in Ecology from Prescott College in Prescott Arizona. She came to Maine by way of Puerto Rico, where she worked for the Forest Service in El Yunque rainforest, and Austin, Texas, where she attended the University of Texas. She is a member of the American Society of Limnology and Oceanography. She is a candidate for the Master of Science Degree in Oceanography from the University of Maine in May, 2003. 